\title{
Financial Incentives in Health: New Evidence from India's Janani Suraksha Yojana
}

Timothy Powell-Jackson *

London School of Hygiene and Tropical Medicine

\section{Sumit Mazumdar}

Institute for Human Development, New Delhi

\author{
Anne Mills \\ London School of Hygiene and Tropical Medicine
}

First Version: $20^{\text {th }}$ September 2011

This Version: $15^{\text {th }}$ June 2015

This paper studies the health effects of one of the world's largest demand-side financial incentive programmes - India's Janani Suraksha Yojana. Our difference-in-difference estimates exploit heterogeneity in the implementation of the financial incentive programme across districts. We find that cash incentives to women were associated with increased uptake of maternity services but there is no strong evidence that the JSY was associated with a reduction in neonatal or early neonatal mortality. The positive effects on utilisation are larger for less educated and poorer women, and in places where the cash payment was most generous. We also find evidence of unintended consequences. The financial incentive programme was associated with a substitution away from private health providers, an increase in breastfeeding and more pregnancies. These findings demonstrate the potential for financial incentives to have unanticipated effects that may, in the case of fertility, undermine the programme's own objective of reducing mortality.

\footnotetext{
*Corresponding author: Timothy Powell-Jackson, London School of Hygiene and Tropical Medicine, 15-17 Tavistock Place, London, WC1H 9SH. Email: Timothy.Powell-Jackson@1shtm.ac.uk. Tel: +44(0)20 7927 2974.

We thank Arnab Acharya and Marcos Vera-Hernandez for helpful comments on an earlier draft of this article. We are grateful to Billy Stewart for his guidance and support during this project. This study was funded by UKaid from the Department for International Development. The views expressed do not necessarily reflect the Department's official policies. All errors are our own.
} 


\section{Introduction}

One of the main challenges for global health is to identify policies and strategies that improve the health of women and children (United Nations, 2010). The traditional focus of much of the medical literature has been on intervention research resulting in unprecedented knowledge on what health technologies work (Bhutta et al., 2008; Campbell and Graham, 2006; Jones et al., 2003). Never before have policymakers in developing countries had such a wealth of evidence at their disposal. Indeed, countries that achieved universal coverage of life-saving interventions have seen rapid reductions in mortality. For example, over the past two decades Thailand, Vietnam and Sri Lanka have developed a comprehensive primary health care system. All these countries between 1990 and 2006 witnessed average yearly reductions in under five mortality of over 5 percent (Rohde et al., 2008). Yet across the developing world more broadly there are large gaps in coverage, particularly amongst the poorest (Bhutta et al., 2010). A key question then is whether there are policies that can be introduced within health systems - termed here health system interventions - which can be shown to improve uptake of priority health services.

In an effort to improve population coverage of health interventions and narrow the differences between income groups, policymakers in developing countries are becoming increasingly bold in their reforms. One promising strategy is to provide financial incentives to individuals who exhibit certain behaviours that improve health. ${ }^{2}$ This is the key feature of various programmes that have become popular in recent years. Whether the incentive takes the form of conditional cash transfers, vouchers or one-off cash payments, the central idea of providing monetary rewards conditional on measurable actions is the same. Financial incentives have courted considerable controversial, with views ranging from "as close as you can come to a magic bullet" to a "form of bribery" (Dugger, 2004; Marteau et al., 2009). Critics point to the theoretical possibility of unintended consequences as well as moral concerns over their use, particularly in a health setting.

This paper studies the early effects of one of the largest cash incentive programmes for health in the world. With an annual expenditure of 8.8 billion rupees or $\$ 207$ million, and an estimated 7.1 million individual beneficiaries, ${ }^{3}$ India's national Janani Suraksha Yojana (JSY) provides cash to women who give birth in a health facility. The JSY provides an ideal testing ground to examine the effects of financial incentives on health. Although officially launched in 2005, implementation of the JSY across districts was incremental, providing variation in its coverage. At the same time, much of the health policy environment in India is common within states, which gives us more confidence that district variation in the JSY is not acting as a proxy for other policy initiatives. A second advantage of this setting is the narrow focus of the JSY on women at childbirth. This provides greater scope for examining unintended consequences of the financial incentives on closely related but non-incentivised behaviours. A third advantage is the scale at which the JSY was

\footnotetext{
${ }^{2}$ In this paper we are interested in demand-side financial incentives, rather than provider payment mechanisms such as pay-for-performance. The latter reward physicians for improvements in quality of care and other measures, and are popular in the US and UK. For brevity, we will use the term financial or cash incentives in health to refer to schemes that target the users of health care.

${ }^{3}$ These figures refer to $2007 / 08$, the financial year closest to our study period.
} 
implemented. This differentiates our study from carefully controlled small scale (incentive) experiments, whose external validity has at times been questioned (Deaton, 2010).

We identify the effect of the JSY on health care seeking behaviour and health status by exploiting the substantial variation in implementation of the JSY across districts. Using data on women who gave birth between 2001 and 2008 from two rounds of India's District Level Health Survey (DLHS), our empirical approach examines whether the JSY can account for cross-district patterns in health care utilisation and health status over time. In estimating the effect of the JSY, this difference-in-difference strategy allows us to control for time invariant unobservables at the district level that influence study outcomes and are correlated with the expansion of the JSY. Using changes in the intensity of the JSY to identify programme impacts, nevertheless, gives rise to endogeneity concerns. Early adopters of the JSY, for example, may have been districts that were highly motivated to make improvements in maternal health services. While we provide extensive robustness checks on our main findings, we are unable to rule out the possibility of confounding and refrain from making strong claims of causality.

Our results show that the JSY was associated with an increase in the proportion of women who give birth in a public health facility. Estimates suggest the magnitude of this effect was reasonably modest. The positive association between the JSY and women giving birth in a public health facility was driven almost entirely by increases in the use of primary health centres and community health centres, providers offering more basic services than those available at the district hospital. In addition, we present evidence on the effect of the JSY on health outcomes, finding no strong evidence of an effect on either neonatal mortality (deaths within 28 days of birth) or one-day mortality (deaths within 24 hours of birth). We note, however, that confidence intervals are not sufficiently tight to reject a modest effect of the JSY on these mortality outcomes.

We also provide evidence on a number of unintended consequences. First, a lack of implementation of the JSY much beyond the public sector means that the financial incentives resulted in women substituting away from giving birth in the private sector. Second, results show that the JSY had a positive, statistically significant effect on pregnancies. Third, we find evidence of indirect benefits. Women in JSY districts were more likely to start early breastfeeding within one hour of childbirth.

This paper contributes to the existing literature by reporting more credible treatment effects than previous studies on the JSY. Our main results are consistent with much of the evidence emerging from conditional cash transfer programmes and small scale incentive experiments. ${ }^{4}$ We also go beyond the typical study of financial incentives in examining unintended consequences. Similar to the findings from studies in Brazil (Morris et al., 2004b) and Honduras (Morris et al., 2004a), we document evidence of unintended effects, which highlight how important it is for policymakers to consider the full range of effects in the design of financial incentive schemes. More generally we connect to a second

\footnotetext{
${ }^{4}$ The systematic literature reviews on conditional cash transfers (Lagarde et al., 2007) and demand-side incentives in health (Murray et al., 2014) provide a detailed summary of much of this evidence.
} 
literature evaluating the impact of health system interventions and policies. This is a wide ranging and challenging area of research (Mills et al., 2008), and one in which much of the existing econometric evidence focuses on the impact of health financing initiatives. ${ }^{5}$

Given that the JSY remains a high-profile federal health programme in India, the findings are of relevance to policy. First, they argue for much better administration of the programme. If disbursement of the JSY cash were improved, the effect on use of formal health care would be greater than at present. Second, the findings reinforce the growing sentiment that demand-side intervention by government can be effective in improving uptake of health services but alone may be insufficient to improve health outcomes. Strengthening the quality of primary health care and the referral system in India is thus a critical complementary strategy, as is staggering supply- and demand-side investments over time such that individuals are encouraged to use services once quality has improved. Third, the findings suggest that financial incentives may be an imprecise tool for changing healthrelated behaviours. They can have unintended health effects, on fertility for example, which may undermine the programme's own objectives. Financial incentives must therefore be used with caution.

The paper is structured as follows. Section II describes the JSY and addresses the theoretical predictions of its impact on health-related behaviours. Section III describes the data. Section IV presents the empirical strategy. Section V presents the main econometric results and includes a discussion of robustness checks. Section VI examines heterogeneity in the impact of the JSY, and Section VII offers concluding comments.

\section{Background}

\section{II.A India's Janani Suraksha Yojana}

Despite the long history of well-intentioned family welfare policies and some recent progress, maternal and child mortality in India remains high. With 72,000 maternal deaths, no other country accounts for a larger proportion of global mortality (Kassebaum et al., 2014). Maternal mortality has fallen by 47 percent from 398 deaths per 100,000 live births in 1997-98 to 178 deaths per 100,000 live births in 2010-12 (Registrar General of India, 2006, 2013). However, the national picture masks enormous differences across states. For example, Kerala's maternal mortality rate is almost five times lower than some of the worst performing northern Indian states (Registrar General of India, 2013). National surveys show that institutional deliveries have increased modestly over time but a large proportion of women continue to give birth at home (International Institute for Population Sciences, 1995; International Institute for Population Sciences and Macro International, 2007). Even when women do reach a health facility to give birth, health workers are often absent (Chaudhury et al., 2006; Muralidharan et al., 2011) and the quality of care they receive is low (Das and Hammer, 2006; Das and Hammer, 2007; Das et al., 2008).

\footnotetext{
${ }^{5}$ See, for example, studies on health insurance (Babiarz et al., 2010; Finkelstein et al., 2011; King et al., 2009; Manning et al., 1987; Thornton et al., 2010; Wagstaff et al., 2009).
} 
It is against this background that the federal government launched the National Rural Health Mission (NRHM) in 2005. Key elements of the programme include large investments in health infrastructure, the deployment of three quarters of a million newly created accredited social health activists as frontline health workers in the community, strategies to stimulate demand for health services, and decentralisation of the health system (Ministry of Health and Family Welfare, 2005). One of the more high profile components of the NRHM is the Janani Suraksha Yojana (translated as "Safe Motherhood Scheme"). It was launched officially in April 2005, with the objective of improving maternal and neonatal health through the promotion of institutional deliveries. ${ }^{6}$ It provides a cash incentive to women who give birth in a public health facility or, in principle, an accredited private health provider (Ministry of Health and Family Welfare, 2006).

The JSY programme designates Indian states as low performing or high performing, varying the cash amount to provide greater incentives in the area of higher priority. Specifically, women in low-performing states are offered 1,400 Rs (\$31) in rural areas and $1,000 \mathrm{Rs}(\$ 22)$ in urban areas, and those in high-performing states are given $700 \mathrm{Rs}(\$ 16)$ in rural areas and $600 \mathrm{Rs}(\$ 13)$ in urban areas. ${ }^{7}$ To put these amounts in perspective, annual Gross National Income per capita was $\$ 1000$ in 2007 and the average amount paid for delivery care in the public sector was $\$ 25$ in 2004 (Bonu et al., 2009). The cash payment is available to all women in the low-performing states; by contrast, it is offered in highperforming states only to women living in households below the poverty line, belonging to scheduled castes and tribes, or those who have had two or fewer live births. The policy stipulates that the cash is to be disbursed to the mother immediately at the institution itself and within a week of delivery.

To provide incentives for health workers who encourage women to give birth in a formal care provider, accredited social health workers are offered a cash payment of between 200 Rs (\$4) and 600 Rs (\$13) for each delivery attended. The JSY also pays 500 Rs (\$11) to women who give birth at home, conditional on less than two living children and a below the poverty line card, but since this is a direct continuation of the cash assistance provided under the National Maternity Benefit Scheme, it does not represent an additional incentive for eligible women to stay at home for delivery.

\footnotetext{
${ }^{6}$ Ethnographic research in the Indian state of Uttar Pradesh casts doubt on the government strategy to encourage institutional deliveries as a means to improve the health of women. Jeffrey and Jeffrey (2010) argue that the context surrounding the government provision of health care presents challenges that neither the NRHM nor the JSY were intended to address. Decades of mistrust of government health services and controversial family planning programmes have left a credibility gap not easily filled by offering financial incentives and investing in new infrastructure. In line with a report by Human Rights Watch (2009), they contend that accountability of government health providers to the population they serve is key and nothing less than "a dismantling of a longstanding political economy of health care provision" will help to remedy the situation.

7 The low-performing states consist of Bihar, Chattisgarh, Jharkhand, Orissa, Uttar Pradesh, Uttaranchal, Rajasthan, Madhya Pradesh, Assam and Jammu and Kashmir.
} 


\section{II.B Anticipated effects}

Consider a financial incentive programme that rewards families in which the woman gives birth in a health facility. ${ }^{8}$ Basic economic theory suggests short-term financial incentives will increase demand for maternal health care. Financial incentives provided to women seeking care in the public sector only change the relative prices of different care seeking options and are thus expected to lead to a substitution away from private health providers and home births (Gertler and Van der Gaag, 1990).

To the extent that public health providers can meet this increase in demand, financial incentives will increase utilisation of health services. If instead public health providers are functioning at full capacity or are unable to increase supply in the short-term, financial incentives will have little impact on utilisation. Moreover, there may be no overall increase in utilisation if the financial incentives contribute to crowding-out of the private sector. Whether an increase in utilisation of public health services improves health outcomes is not clear-cut, and will depend on differences in the clinical quality of care between the various health care seeking choices. We would expect the narrowest difference in quality to be between public and private health providers, particularly in terms of clinical as opposed to interpersonal dimensions of quality.

While the financial rewards provide explicit incentives to use maternal health services, implicitly they also serve to incentivise pregnancy. This effect may manifest itself in terms of a reduction in birth spacing or an increase in total lifetime children for women who otherwise would not have become pregnant. We also anticipate indirect effects as financial incentives increase women's exposure to health information. Greater contact with health staff exposes women to more information on healthy behaviours concerning the mother and her neonate. Behaviors shown to have an impact on health outcomes include wrapping the baby within 30 minutes of childbirth, initiating breastfeeding within one hour, and dressing the cord with antiseptic (Darmstadt et al., 2005).

\section{II.C Evidence on the JSY}

There have been a number of studies on the JSY, some of which have collected primary household data (Hunter et al., 2014). For the most part these have been descriptive, documenting progress in the implementation of the programme (Devadasan et al., 2008; Malini et al., 2008; Verma et al., 2010). By contrast, Lim et al (2010) make claims as to the causal effect of the JSY. Impact estimates are based on three identification strategies: individual-level matching, a modified before and after design, and a two-period district level difference-in-difference approach. The main conclusion from the analysis is that the JSY increased substantially use of maternal health care and reduced neonatal mortality.

The study by Lim et al (2010) has several important limitations. First, the headline results are based on the matching and modified before and after design, while estimates from the difference-in-difference analysis are given less emphasis on the basis that they lack power. Having imprecise estimates from the district level analysis does not provide justification to

\footnotetext{
${ }^{8}$ For a thorough discussion of the economic rationale of conditional cash transfers, see Fiszbein and Schady
} (2009). 
highlight other methods simply because they have more power. Second, individual matching based on whether women did and did not receive the JSY cash is unlikely to provide credible estimates of effect because there is reverse causality (women receive the cash when they give birth in a health facility) and individual unobservables correlated with outcomes are likely to be important factors in determining who takes up the programme. The modified before and after study design is also problematic since it must rely again on the strong assumption of conditional independence (Imbens and Wooldridge, 2009). Third, a strategy that controls for observables at the district level is more credible because selection is now at the policy level where it is likely to be based on observed measures of need. However, the share of births in a district in which the woman received the JSY cash is an inappropriate measure of treatment because it is mechanically linked to the fraction of women giving birth in a facility. By definition, it captures not only the availability of the programme but also demand side factors driving utilisation.

This paper addresses the limitations of past research on the JSY. Given the high profile nature of the programme, we set out to provide more credible estimates of impact across a wide range of behaviours. We also provide new findings on how the JSY affects health seeking choices between different types of provider, the heterogeneity of impacts, and whether the JSY has unintended consequences.

\section{Measures and Data}

\section{III.A Study Outcomes}

Data on the study outcomes come from the household component of the District Level Health Survey (DLHS), a repeated cross-section survey designed to provide estimates on maternal and child health and service utilisation at the district level in India (International Institute for Population Sciences, 2010). We use data from two rounds of the household survey. The DLHS-2, conducted over the period 2002-04, interviewed 507,622 currently married women in 593 districts. The DLHS-3 was carried out in 2007-08 and interviewed 643,944 currently married women in 611 districts.

The married woman questionnaire is modelled closely on India's established National Family and Health Survey. It contains measures of health care utilisation and health status that the JSY would be expected to improve. Our main utilisation outcome is births in a health facility, measured using information on the place of delivery of the woman's most recent birth. The analysis also considers variants on this outcome, such as the type of health provider chosen, whether a health worker was in attendance and the type of procedure performed at delivery.

Our main measures of health status are one-day mortality (death of a baby within 24 hours after being born alive) and neonatal mortality (death of a baby within 28 days after being 
born alive). Both are measured using information on the birth history of women. ${ }^{9}$ The financial year of the most recent delivery and each live birth is established using information on the year and month reported by women. ${ }^{10}$ The DLHS-3 limits the recall period of birth histories to $1^{\text {st }}$ January 2004, while those in DLHS-2 are not truncated. However, to ensure recall periods are approximately the same in the two survey rounds, we drop all observations prior to $1^{\text {st }}$ April 2001. Thus, when we stack the data from the two survey rounds, we have observations in every financial year from 2001/02 to 2007/08.

An important contribution of this paper is to consider the effect of the JSY on a second set of outcomes that we refer to as unintended consequences of the programme. These are outcomes that did not feature in the stated objectives of the programme and are in this sense unintended. They include the likelihood of giving birth in a private health facility, getting pregnant in a given year, and breastfeeding immediately after childbirth. We establish whether a woman was pregnant in a given year using the pregnancy histories contained in the survey. To measure breastfeeding, women were asked if and when they started breastfeeding the child of their most recent delivery. We focus on breastfeeding within the first hour, when information from health providers on the benefits of timely breastfeeding is most likely to take effect. All outcomes in this study are comparable across the two survey rounds, both in terms of how they are defined and the interview questions used to elicit the required information.

Summary statistics on the outcome measures before and after the start of the JSY are shown in Panel A of Table 1. Neonatal mortality fell over the course of the two periods from 33 to 27 deaths per 1,000 live births. Facility births saw a modest increase over time but still more than half of women continued to give birth at home. Around $8 \%$ of women gave birth by caesarean section and a further $2 \%$ had an assisted delivery with forceps or a ventouse, neither of which changed much over time. By contrast, use of antenatal care and breastfeeding improved over time. The proportion of women who reported being pregnant in any given year was $8 \%$. In addition to information on study outcomes, we exploited data on a broad range of socio-demographic characteristics as detailed in Panel B of Table 1.

The data contain a district identifier which we use to estimate specifications with district fixed effects. However, because the administrative boundaries of some districts changed in the period between the two surveys, we map new districts in the DLHS-3 onto their old counterparts in the DLHS-2 data. In most cases this was possible, leaving 587 districts that were consistently defined across the two datasets. ${ }^{11}$ In estimating the effect of the JSY on care seeking behaviour and health status, for lack of data we assumed that the district in which women are residing at the time of interview was the same as the one where she gave

\footnotetext{
${ }^{9}$ Unless truncated, a birth history documents every birth a woman has had during her lifetime. It typically includes the birth outcome, sex of the child, birth order, month and year of childbirth, age of woman at childbirth and, if the child died, age at death.

${ }^{10}$ We work in financial years ( $1^{\text {st }}$ April to $31^{\text {st }}$ March) throughout because the government's annual budgetary cycle is likely to correspond more closely to the introduction of the JSY than calendar years.

${ }^{11}$ In cases where the geographical boundaries of newly created districts cut across two or more old districts, we were unable to map the new districts onto their old counterparts.
} 
birth. Available evidence suggests that residents of a district rarely travel to other districts to seek healthcare. ${ }^{12}$

\section{III.B JSY Coverage}

Our estimation strategy rests on there being variation in the implementation of the JSY. We exploit such variation at the district level, the administrative unit directly below the Indian state which has responsibility for planning and implementation of federal and state policies. If the financial incentives of the JSY are to bite, households should be exposed to information about the programme and financial incentives should reach eligible women. ${ }^{13}$ Data on the latter provide the foundation for our measure of JSY penetration and is based on responses to the question: "Did you receive any government financial assistance for delivery care under the Janani Suraksha Yojana or state-specific scheme.” Specifically, we use the term JSY coverage to refer to the number of women who gave birth in a public facility and received the cash as a proportion of women who gave birth in a public facility. ${ }^{14}$ Full coverage thus implies every woman giving birth in a public health facility receives the financial incentive. Because coverage of the JSY is constructed from the sample of women who delivered in a public facility, it is primarily a supply-driven measure of the intensity of implementation. It is affected not by the demand for care but rather the government's ability to make the programme available to women at the level of service delivery, an assertion we test below.

Our measure of JSY implementation is based on beneficiary data from households rather than administrative data (eg. budget releases or district expenditure) for several important reasons. First, such administrative data may reflect only the intention of the government, whereas information on whether a district has JSY beneficiaries implies that the government has taken all the necessary steps to start the programme on the ground. Second, there is no reason to believe administrative data would be any more reliable than household data. In fact, such information is easy to manipulate systematically and incentives are likely to be there to do so.

Table 2 shows the expansion of the JSY programme over time. In its first year, JSY coverage was less than $10 \%$ in 279 of the 587 districts, while only a handful of districts had coverage over $50 \%$. Over time coverage of the JSY at the district level increased. In the third year of the programme, JSY coverage was more than $10 \%$ in 489 of the 587 districts.

\footnotetext{
${ }^{12}$ In a recent survey of women in Uttar Pradesh, we find that only $1.8 \%$ of women giving birth in a facility travelled outside of their district for delivery. Sood et al (2014) find little evidence of cross-district healthcare seeking in a study of health insurance in Karnataka.

${ }^{13}$ A study carried out in 2008 in the high-focus states of Bihar, Orissa, Uttar Pradesh, Madhya Pradesh and Rajasthan found that four-fifths of women were aware of the scheme and almost half of women giving birth in a health facility received the JSY cash (UNFPA, 2009).

${ }^{14}$ Due to imprecise wording, this question picked up responses that refer to the National Maternity Benefit Scheme (MBS), an initiative that preceded the JSY up until its official introduction in April 2005 (see Section II for more detail). This explains why 7.4 percent of women giving birth in a health facility report receiving a cash payment in 2004/05, before the JSY was even official government policy. We code the JSY coverage variable as zero prior to the official start of the programme. While the JSY is not limited to the public sector, our measure of coverage considers only public sector recipients of the financial incentive because only a few nonstate health providers - in contrast to all health providers in the public sector - were accredited and able to participate in the JSY.
} 
Figure 1 illustrates well the considerable variation in the expansion of the programme between districts and over time. It also provides descriptive evidence of the relationship between the JSY programme and facility births. Districts where the JSY was progressively better implemented appear to have the largest increases in the proportion of women giving birth in government health facilities.

In anticipation of the empirical analysis, we recognise that variation in the coverage of the JSY across districts is unlikely to be random. Discussions with policymakers and other stakeholders engaged with the JSY suggest that the introduction of the programme was prioritised in socioeconomically disadvantaged places. At the national level, the JSY was explicitly prioritised according to high-focus and low-focus states. More importantly, however, interviews indicated that the JSY was prioritised within states at the district level. For example, in the state of West Bengal, health sector reforms including the JSY gave particular attention to six focal districts, identified on the basis of health indicators, poverty and socially marginalised population groups. ${ }^{15}$

Empirically we can examine the relationship between JSY coverage and several socioeconomic variables highlighted by policymakers. In Table A1 of the Appendix, we run a district-level regression of JSY coverage on poverty incidence, the tribal population share and average household wealth showing that the three variables of interest are strong predictors of JSY coverage. Broadly this remains true when we include state fixed effects. The data support the qualitative evidence in showing the role of these district characteristics in influencing the decision on where to introduce the JSY. In the final column we see that the share of births in a government facility in the year before the JSY does not predict subsequent implementation of the programme, suggesting that our measure of JSY is not picking up demand side factors influencing utilisation of health services.

\section{Empirical Strategy}

Our identification strategy uses a difference-in-difference approach to estimate the impact of the JSY on our study outcomes. We compare changes over time in health care utilisation and health status with changes in the intensity of the JSY programme. More precisely, in our basic specification we run a regression of each outcome on JSY coverage while controlling for year and district fixed effects. The fixed effects absorb variation due to common temporal shocks and time-invariant district factors.

To increase the strength of causal inference, we also control for a wide range of potential confounding factors. Formally, let $y_{i d t}$ denote our outcome, a binary measure of service utilisation or health status for observation $i$ in district $d$ in year $t$. Let JSY $d t$ denote our measure of programme coverage in district $d$ in year $t$. Our specification takes the form:

$$
y_{i d t}=\beta_{0}+\beta_{1} \mathrm{JSY}_{d t}+\vartheta_{t} Z_{d} \beta_{2}+X_{i d t} \beta_{3}+\omega_{d}+\tau_{t}+\varepsilon_{i d t},
$$

15 Scheduled tribes are historically disadvantaged people in India, given explicit recognition in India's Constitution. 
where $\omega_{d}$ and $\tau_{t}$ are district and year fixed effects respectively; $X_{i d t}$ is a vector of individual demographic characteristics including education of the mother, education of the husband, maternal age, household wealth, the recall period (months between interview and birth of child) and dummies for (categories) of urban residence, religion, ethnicity, parity, multiple births and survey round; and $Z_{d}$ is a vector of district-level characteristics. To model the effect of the programme flexibly, $\mathrm{JSY}_{d t}$ enters the regressions as dummy variables that correspond to the following levels of coverage: $10-25 \%, 25-50 \%$ and $>50 \%$. We cluster our standard errors at the district level.

To address several sources of potential confounding, we include interactions between the year of birth and the share of the district population below the poverty line, the tribal population share, and the district mean of the household wealth asset score, represented by the term $\vartheta_{t} Z_{d}$. Data used to generate these district-level variables come from the DLHS$3,{ }^{16}$ which means we are controlling for differential trends based on 2008 values rather than actual trends.

As is clear from equation (1), we run regressions of each outcome using individual level data to make the most of the rich micro dataset at our disposal. This allows us to include controls for a range of individual demographic characteristics that might affect health care utilisation and health status. In using individual level data, we note that the unit of observation differs according to the outcome. Each observation is a delivery (the most recent only) in the utilisation equations, and a live birth in the mortality equations. In the analysis of pregnancies, the unit of observation is woman-year but we must rely on data from the DLHS-3 only (2004-2008) because the DLHS-2 did not collect information on pregnancy histories.

\section{Main Results}

\section{V.A Use of Health Care and Mortality}

Table 3 presents estimates of the effect of the JSY on various measures of health care utilisation. Panel A present results from our basic specification which includes district and year fixed effects. In Panel B, we additionally control for district characteristics and individual demographics.

Column (1) shows that the JSY was associated with an increase in the percentage of women giving birth with a health worker in attendance at delivery. Specifically, the likelihood of giving birth with a health worker was 5.6 percentage points higher in districts with JSY coverage $>50 \%$ than districts with coverage $<10 \%$. At lower levels of JSY coverage, there

\footnotetext{
${ }^{16}$ Our measure of poverty is constructed using information relating to the government system of identifying poor households. Specifically, it is based on responses to the question: "Does this household have a below the poverty line (BPL) card?" Because we are interested in controlling for sources of endogeneity that arise from government decision making processes, this poverty measure - rather than one measured perhaps more reliably in terms of household consumption - is particularly appropriate for our purposes.
} 
was no significant association. Columns (2) and (3) show the effect of the JSY on health facility births with the same pattern of results. The point estimates indicate that the programme at levels of coverage $>50 \%$ was associated with a 7.5 percentage point increase in facility births and an 11 percentage point increase in public facility births. Columns (4) to (6) present the effect of the JSY on utilisation by each type of public health facility. These results imply that the impact on public health facility births was driven largely by increases in births at community health centres and primary health centres. By contrast, district hospitals accounted for only a small proportion of the treatment effect. These findings suggest an expansion in uptake of delivery care services at public health providers below the district hospital.

Column (7) shows that the JSY did not have an effect on utilisation of antenatal care services. The point estimates for three or more antenatal care visits are small and statistically insignificant and the result holds irrespective of how we define the antenatal care outcome (result not shown). ${ }^{17}$ This finding is reassuring for our empirical strategy because we anticipate no large effect given that the financial incentive in the JSY was not explicitly tied to the use of antenatal care. It suggests that the JSY treatment indicator is not simply acting as a proxy for other government policies aimed at strengthening maternal health services. Further results showing the effect of the JSY on the rate of caesarean sections and assisted deliveries are reported in Table A4 of the Appendix. The JSY at coverage levels $>50 \%$ was associated with a decrease in the caesarean section rate and an increase in assisted deliveries. The negative impact on the caesarean section rate is most likely explained by the shift away from the private sector (reported in Section V.C) where the vast majority of caesarean sections are conducted. ${ }^{18}$

When we include extensive controls for potential confounders the point estimates remain essentially the same (Panel B of Table 3). For example, the likelihood of giving birth in a government health facility is 10 percentage points higher in districts with JSY coverage $>50 \%$ than districts with coverage $<10 \%$. When we include in the model a single treatment variable indicating JSY coverage $>10 \%$, the findings are qualitatively similar (Table A2). This model is more akin to an intention-to-treat analysis in the sense that the estimates reflect better the impact of the JSY irrespective of how well districts implemented the programme. When we include in the model JSY coverage as a continuous variable the findings remain qualitatively largely unchanged (Table A3). For example, a 1 percentage point increase in JSY coverage is associated with a 0.2 percentage point increase in government facility births.

We next turn to the mortality results (Table 4). The results in column (1) show that there is no strong evidence the JSY reduced neonatal mortality. None of the coefficients on the JSY coverage dummies are significant at the 5 percent level. At coverage levels $>50 \%$ the JSY is associated with a reduction in neonatal mortality of 3.1 deaths per 1,000 live births which

\footnotetext{
${ }^{17}$ Alternative measures of antenatal care utilisation include the number of antenatal care visits. Using a Poisson regression we find no effect on the number of antenatal care visits.

${ }^{18}$ By contrast, at the first level of referral in the public sector only 18 percent of community health centres offer caesarean sections and less than 10 percent have blood storage facilities (International Institute for Population Sciences, 2010).
} 
is significant at the 10 percent level. In the specification with the full set of controls, we are able to reject with 95 percent confidence a negative effect of the JSY larger than 5.9 deaths per 1,000. In columns (2) to (4) we separate out neonatal mortality into its constituent parts since we anticipate that if the JSY were to reduce mortality, the effect would be strongest within the first 24 hours of childbirth when maternity care is provided. Results in column (2) show a negative effect of the JSY on one-day mortality. There is a slight suggestion of an effect of the JSY at coverage levels $>50 \%$. In the specification with the full set of controls, we are able to reject with 95 percent confidence a negative effect of the JSY larger than 4.5 deaths per 1,000. Columns (3) and (4) confirm that there was no effect of the JSY on later neonatal mortality, which provides some confidence that the findings in column (2) are not spurious for we would not anticipate maternity care to have a direct effect on the mortality of the baby after the mother is discharged to go home. The mortality findings remain similar when we include additional controls (Panel B of Table 3), or replace the JSY coverage dummies with either a single binary treatment variable of $>10 \%$ coverage (Table A2 of the Appendix) or a continuous treatment variable (Table A3 of the Appendix).

These findings suggest that the JSY did not have a large effect on neonatal and one-day mortality but the confidence intervals leave open the possibility that the JSY had a modest effect at high levels of programme coverage. Why was the association between the JSY and mortality, at best, only modest? One possibility is that the effect on utilisation was not sufficiently large to translate into better health outcomes. A second explanation points to the poor quality of care in the public sector (Chaturvedi et al., 2014; Hulton et al., 2007; Nagpal et al., 2015; Stanton et al., 2014), and the fact that the JSY increased uptake of maternity services at health facilities below the district hospital, which are not equipped to manage emergency complications at childbirth.

\section{V.B Magnitudes and Simple Cost-Effectiveness}

According to our estimates, the JSY encouraged an additional 710 thousand women in India to give birth in a health facility in $2007 / 08 .{ }^{19}$ In a quick calculation using programme expenditure data, we estimate that the government spent \$292 of JSY money for each additional facility birth. ${ }^{20}$ Because the financial incentive is given irrespective of whether the individual would have given birth in the health facility in the absence of the JSY, the cost per marginal visit is much higher than the value of incentive. Using data on the cost of delivery from Bonu et al (2009), we calculate a total cost of $\$ 415$ for each additional facility birth. ${ }^{21}$ However, while a cost to the government, one could argue that the financial incentives should not be considered a cost at all since they represent a transfer of resources.

\footnotetext{
${ }^{19}$ This estimate is calculated by applying the coefficients in column 2 of Table 3 to the respective number of live births in each set of districts categorised according to the various levels of JSY coverage in 2007/08.

${ }^{20}$ This figure is likely to represent a minimum cost since we have not factored in administration of the JSY, whose economic cost is not captured by programme expenditures. If we assume conservatively that administration costs represent 10 percent of programme spending, expenditure per additional facility birth was $\$ 321$.

${ }^{21}$ Bonu and colleagues (2009) report estimates of household expenditure on delivery care from India's National Sample Survey in 2004. We use household expenditure on a private facility birth on the basis that this better reflects the full economic cost of giving birth. Because the public sector is subsidised, expenditure on a public facility birth is likely to be a gross underestimate. While crude, our cost estimate gives a sense of the order of magnitude. Note that the financial data are adjusted for inflation.
} 
The cost to society then is only the deadweight loss associated with taxation, the administrative cost of running the JSY and the cost of providing delivery care services.

There is a growing literature on demand-side incentives in health against which to compare the magnitudes of our estimated effects. In terms of the JSY, we compare our results against the study by Lim et al (2010) which suggests that the programme increased use of antenatal care (three visits or more) by 11 percentage points, increased facility births by 44 to 49 percentage points, and reduced neonatal mortality by 2 to 6 deaths per 1,000 live births. ${ }^{22}$ Clearly our conclusions are much less encouraging with regards to the healthcare utilisation findings. The estimates of impact on neonatal mortality are of the same order magnitude in the two studies. The key difference is the mortality effects in Lim et al (2010) are statistically significant in two of the three identification strategies they use. Beyond the JSY, there is a strong body of experimental evidence that comes from studies of conditional cash transfers in Malawi (Baird et al., 2012), Mexico (Fernald et al., 2008; Gertler, 2000; Gertler, 2004), Nicaragua (Maluccio and Flores, 2005), Brazil (Morris et al., 2004b), Ecuador (Paxson and Schady, 2008), Honduras (Morris et al., 2004a), one-off financial incentives in Malawi (Thornton, 2008), and non-financial incentives in India (Banerjee et al., 2010), although few are specific to maternal health. The interventions in these studies were targeted towards poor families and most provide some evidence of positive effects on utilisation of health services and immunization coverage.

\section{V.C Unintended Consequences}

Our results thus far have focused on outcomes which, according to the stated objectives of the programme, the JSY was intended to improve. However, high powered incentives have the potential to influence a broad range of behaviours, which in turn may have both positive and negative implications for welfare. Here we study three possible effects of such incentives. First, we expect the JSY to increase demand for public maternity services, in part, through a substitution away from private health providers. Second, some have argued that cash payments for delivery or child health care provide an incentive to become pregnant. Third, financial incentives for delivery care may have positive benefits through changes in health-related behaviours subsequent to childbirth, such as breastfeeding. The idea is that women who give birth in a health facility are more likely to be exposed to information on the benefits of timely breastfeeding. ${ }^{23}$

Table 5 presents the results on unintended consequences of the JSY. Column (1) shows that the JSY was associated with a reduction in utilisation of maternity services in the private sector. For reference, we reproduce in column (2) previous findings on utilisation of services in the public sector. Substitution away from the private sector accounts for a sizeable proportion of the effect of the JSY on public facility births. Data from the DLHS

\footnotetext{
${ }^{22}$ See the Online Appendix for a more detailed comparison of the two set of findings.

${ }^{23} \mathrm{We}$ also considered other health-related behaviours potentially influenced by exposure to information during childbirth, including postnatal care seeking, whether the baby was immediately wiped dry and wrapped, and whether a sterilized blade was used to cut the umbilical cord. The DLHS, however, provides no scope for measuring these outcomes consistently between the two survey rounds. Child immunization was not regarded as a plausible indirect outcome given the long time lag between childbirth and vaccinations.
} 
lend support to these findings by showing that the JSY has been predominantly a public sector programme despite the stated policy to involve private health providers. Only 10 percent of JSY beneficiaries nationwide gave birth in a private health facility.

We next look at the results on pregnancies. ${ }^{24}$ They show in column (4) that the JSY was associated with a modest increase in the likelihood of a woman being pregnant in a given year. This result is plausible when we consider that it probably reflects a reduction in birth spacing rather than an increase in the total lifetime number of children. Either way, there are implications for health given that both birth spacing and total fertility are important underlying causes of maternal and neonatal mortality (Zhu et al., 1999). Other studies have shown that fertility is amenable to change in the face of conditional cash transfers (Morris et al., 2004a; Stecklov et al., 2006) and cable TV (Jensen and Oster, 2009) and estimates reported in these studies are much greater than the effect of the JSY found here.

The risk of increased childbearing was partly anticipated by policymakers in the design of the JSY and these safeguards provide some motivation to scrutinise the validity of the pregnancy results. If women with more than two children were unable to receive the JSY cash, why would they be incentivised to become pregnant? However, the policy of limiting the cash payment to women with two or fewer children applied only to the low focus states and was difficult to implement. DLHS-3 data show that the probability of a woman receiving the cash incentive after giving birth in a public health facility is statistically the same across parity groups, a pattern which suggests policy attempts to mitigate this unintended consequence were not implemented. ${ }^{25}$

Columns (5) and (6) of Table 4 report the results on breastfeeding within the first hour and the first 24 hours of birth, respectively. Both sets of results suggest that the JSY was associated with an increase in breastfeeding soon after childbirth, consistent with increased exposure to information from health workers around the time of childbirth.

\section{V.D Robustness}

Our estimates of effect are credible in so far as our identifying assumption holds that JSY coverage is orthogonal to the error term. While it is by definition impossible to test this assumption formally, we can mitigate concerns of bias due to non-random placement of the JSY by pursuing several robustness checks. Pre-trends are a commonly used tool to examine whether the assumption underpinning the difference-in-difference approach is credible. Specifically, if districts with different levels of coverage of the JSY have similar

\footnotetext{
${ }^{24}$ For women who report being pregnant at the time of interview, we have no information on when they became pregnant to assign the pregnancy to a specific year. We therefore use a random number generator, constrained between three and nine, to determine the number of months a woman is pregnant, if pregnant at the time of interview. The pregnancy for these women is thus assigned to one of two possible years. Another approach might seek to model seasonality in pregnancy. The data, however, show that the probability of pregnancy differs little across months of the year.

25 The percentage of women who received the cash incentive conditional on giving birth in a public health facility is as follows: first birth (33.0 percent); second birth (32.5 percent), third birth (29.1 percent); fourth birth (33.4 percent); and fifth or higher birth (35.5 percent). While these data are not perfect - the number of times a woman has given birth does not necessarily equal the number of living children - they are highly suggestive of the policy not being effective in practice.
} 
trends in outcomes prior to the start of the programme, we can be more confident of our estimates. Descriptive data are reassuring in this respect. Pre-trends plotted separately for districts in each of the four categories of JSY coverage are similar (see Online Appendix). More formally, using only data prior to the start of the JSY programme, we examine whether pre-trends differ according to future JSY coverage. As indicated by the coefficient on the interaction between years since the start of the data period and future JSY coverage in Table A5 of the Appendix, we are able to accept at the 5 percent level the null hypothesis of equal pre-trends. ${ }^{26}$

We then examine whether JSY coverage is correlated with the characteristics of individual women. We have argued that JSY coverage is primarily a supply-side measure. This check provides evidence on whether JSY coverage is correlated with demand once we control for selection at the policy level. We regress the JSY coverage variable on the full set of individual-level demographic controls while including the district covariates. Table A6 of the Appendix presents the results of this robustness check. The results in column (1) are simply to show that when we fail to account for selection at the district level, individual demographics are a strong predictor of JSY implementation. An F test of the joint hypothesis that none of the demographics is correlated with JSY coverage is rejected $(\mathrm{p}=0.015)$. When we do control for selection at the district level, in column (2), we see that these same demand-side factors are no longer correlated with implementation of the JSY $(\mathrm{p}=0.290)$ despite the fact that, as column (3) shows, they are strong predictors of utilisation of government delivery care services $(\mathrm{p}=<0.001)$. Together these results give us more confidence that the variation in our measure of JSY coverage is largely supply-driven.

We performed a range of further robustness checks. These are summarised in Table A7 of the Appendix. Long difference regressions using data at three-year intervals yield coefficients similar to the main results (Panel A). Dropping districts with a high neonatal mortality rate of over 50 deaths per 1,000 live births (6 percent of districts) leads to almost identical coefficients (Panel B). Excluding districts in states where there was no parity condition connected to the receipt of the cash (ie. states designated by the programme as low priority) leaves the point estimates essentially the same (Panel C). Finally, allowing for the possibility of confounding trends, by including state-specific time trends, reduces the magnitude of the estimates although the general pattern of results remains unchanged (Panel D).

\section{Heterogeneity in Impacts}

We first examine how the effect of the JSY is distributed along several standard dimensions of socioeconomic status, namely maternal education and household wealth. These can be considered demand-side factors that may modify the effect of the JSY on health care seeking behaviour. We then study whether there is a dose-response relationship. By exploiting the fact that the JSY substantially varies the amount of cash paid to women in

${ }^{26}$ These findings hold if we interact time with categories of JSY coverage (result not shown). 
different places, we are able to learn more about a fundamental policy parameter. The amount of cash paid to women is more generous in rural areas than urban areas within high focus states, and in high focus states than low focus states. We therefore conduct two subgroup analyses along these lines.

Table 6 presents the JSY treatment effects across various subsamples with public facility births as the dependent variable. The first two columns show that the effect of the JSY on utilisation is greater amongst women with no education than women with some education ( $p$ value of the difference is $<0.001$ ). The next two columns compare the treatment effect between the two wealth groups, with point estimates showing a similar pattern to the education results. Poorer women are more likely to give birth in a public health facility in response to the JSY than richer women ( $p$ value of the difference is $<0.001$ ). The results in the remaining four columns show that the effect of the JSY was larger in places where the amount of cash offered to women was greater. The response to the JSY was greater in rural areas than urban areas ( $\mathrm{p}$ value of the difference is 0.058 ) and greater in low focus than high focus states ( $p$ value of the difference is $<0.001$ ). When considered relative to the baseline mean, the differences between the subgroups are clearly large.

\section{Conclusions}

In this paper, we have examined the association between one of the world's largest demandside financial incentive programmes and health-related outcomes in India. Consistent with much of the literature outside of India, we find that the financial incentives in the JSY are associated with an increase in the use of formal health services, particularly at lower levels of the public health system. The increase in use of formal maternal health care due to the programme was modest. Our findings on neonatal mortality show no strong evidence of an effect, although confidence intervals are not sufficiently tight to reject modest effects of the JSY on mortality.

A persuasive explanation for the mortality finding is that the JSY incentivised women predominantly to health facilities whose purpose was not to manage life-threatening complications. However good the quality of care in health institutions below the district hospital, it may remain inadequate to save the lives of women and their baby, particularly when obstetric emergencies require intensive rather than obstetric care (Costello et al., 2006). Having a fully functional referral system is thus critical for the success of any intervention which seeks to increase uptake of institutional delivery care (Campbell and Graham, 2006). Existing evidence suggests that the quality of maternity services and the referral system in the public sector remains poor in India (Chaturvedi et al., 2014; Hulton et al., 2007; Nagpal et al., 2015; Stanton et al., 2014).

We have argued that high powered incentives have the potential to influence a broad range of behaviours, intended or otherwise. Any evaluation of financial incentives should go beyond the narrow objectives of the programme to examine potential unintended consequences. Our pregnancy results are striking because they suggest a pathway through 
which the programme's own objective of reducing maternal and neonatal mortality may be undermined. It also serves to demonstrate the importance of anticipating such risks in the programme design and, in turn, ensuring appropriate measures are put into practice.

A further point of discussion relates to the generalisability of our findings to an expanded JSY programme, say five years down the line. It is certainly possible that the effect of the programme has increased as it has matured. Women will only be incentivised by the programme if they know about the benefits but it takes time for such information to spread in the population. Alternatively, the effects in this paper may be larger than those observed when the JSY finally reaches all districts in India. Early implementation of the JSY was understandably prioritised in districts that contain poorer populations and evidence on impact heterogeneity suggests that these districts were the ones where the greatest benefits from the programme could be realised. Thus, extending our estimates of effect to the period since 2008 may not provide a good approximation to the true impact of the programme.

The collective evidence in this paper, on both intended and unintended effects, points towards the need for policymakers to be cautious in the use of financial incentives. For example, even though it is self-evident that the supply-side must be in place if demand-side financial incentives are to work, there is a proliferation of schemes in countries where the quality and even availability of care are vastly inadequate. Future research on this topic should broaden its scope to address questions around their long-term effects, and the potential harms they may cause (Lagarde et al., 2007). 


$\begin{array}{cc}\begin{array}{c}2001 / 02-2004 / 05 \\ \text { (before JSY) }\end{array} & \begin{array}{c}2005 / 06-2007 / 08 \\ \text { (during JSY) }\end{array} \\ \end{array}$

Panel A. Study outcomes

Neonatal mortality (per 1,000 live births)

33.0

26.6

One-day mortality (per 1,000 live births)

16.1

13.0

Health worker in attendance at delivery (\%)

46.0

49.1

Delivery in a health facility (\%)

38.7

43.7

Public health provider (\%)

20.0

25.5

Private health provider (\%)

18.7

18.2

Caesarean section (\%)

7.3

8.1

Assisted delivery (\%)

2.6

1.8

At least three antenatal care visits (\%)

$43.6 \quad 46.9$

Breastfeeding within one hour of birth (\%)

31.1

39.9

Pregnant in a given year (\%)

7.7

Panel B. Individual covariates

Urban (\%)

26.1

18.3

Hindu (\%)

76.3

76.0

Scheduled caste (\%)

18.4

19.0

Scheduled tribe $(\%)$

16.7

17.6

Other backward caste / tribe (\%)

40.0

40.6

Maternal age (years)

24.6

25.0

Number of live births

2.64

2.54

Woman's education (grades completed)

4.36

4.47

Husband's education (grades completed)

6.66

6.62

Household wealth asset (score)

$-0.018$

$-0.053$

Notes: Summary statistics are based on data from the DLHS-2 and DLHS-3, including observations over the period 2001/02 - 2007/08. The unit of observation is a woman's most recent delivery, except in the case of neonatal mortality (live birth) and pregnant this year (woman-year). Assisted delivery includes the use of forceps or a ventouse. The household asset wealth score is generated by applying principal component analysis to a set of household asset ownership variables. 
Table 2. JSY Coverage

\begin{tabular}{lccc}
\hline & $2005 / 06$ & $2006 / 07$ & $2007 / 08$ \\
\hline Districts with & & & \\
JSY coverage $0-10 \%$ & 279 & 163 & 144 \\
JSY coverage $10-25 \%$ & 151 & 137 & 162 \\
JSY coverage $25-50 \%$ & 123 & 164 & 183 \\
JSY coverage $>50 \%$ & 34 & 123 & 587 \\
Total sample & 587 & 587 &
\end{tabular}

Notes: Based on data from the DLHS-3. 
Table 3. Association of JSY with Use of Maternal Health Care Services

\begin{tabular}{|c|c|c|c|c|c|c|c|}
\hline \multirow{3}{*}{ Dependent variable: } & \multirow{3}{*}{$\begin{array}{l}\text { Health worker in } \\
\text { attendance at delivery } \\
\text { (1) }\end{array}$} & \multirow{3}{*}{$\begin{array}{l}\text { Delivery in a } \\
\text { health facility } \\
\text { (2) }\end{array}$} & \multirow{3}{*}{$\begin{array}{c}\text { Delivery in public } \\
\text { health facility } \\
\text { (3) }\end{array}$} & \multicolumn{3}{|c|}{ Delivery by type of public health facility } & \multirow{3}{*}{$\begin{array}{l}\text { At least three } \\
\text { ANC visits } \\
\text { (7) }\end{array}$} \\
\hline & & & & Hospital & $\begin{array}{l}\text { Community } \\
\text { health centre }\end{array}$ & $\begin{array}{c}\text { Primary health } \\
\text { centre }\end{array}$ & \\
\hline & & & & (4) & (5) & (6) & \\
\hline \multicolumn{8}{|c|}{ Panel A. Baseline model } \\
\hline \multirow[t]{2}{*}{ JSY coverage $10-25 \%$} & -0.0053 & -0.0061 & -0.00072 & 0.00081 & 0.0010 & 0.0023 & 0.00071 \\
\hline & $(0.0055)$ & $(0.0054)$ & $(0.0049)$ & $(0.0044)$ & $(0.0017)$ & $(0.0019)$ & $(0.0053)$ \\
\hline \multirow[t]{2}{*}{ JSY coverage $25-50 \%$} & 0.0017 & 0.0072 & $0.019 * * *$ & 0.0033 & $0.0092 * * *$ & $0.011 * * *$ & 0.0052 \\
\hline & $(0.0061)$ & $(0.0061)$ & $(0.0055)$ & $(0.0047)$ & $(0.0023)$ & $(0.0027)$ & $(0.0061)$ \\
\hline \multirow[t]{2}{*}{ JSY coverage $>50 \%$} & $0.056 * * *$ & $0.075 * * *$ & $0.11 * * *$ & $0.028 * * *$ & $0.040 * * *$ & $0.051 * * *$ & 0.010 \\
\hline & $(0.0090)$ & $(0.0093)$ & $(0.0086)$ & $(0.0061)$ & $(0.0045)$ & $(0.0039)$ & $(0.0075)$ \\
\hline \multicolumn{8}{|c|}{ Panel B. Baseline model with district and individual controls } \\
\hline \multirow[t]{2}{*}{ JSY coverage $10-25 \%$} & -0.0021 & -0.0033 & -0.0015 & -0.00011 & 0.0016 & 0.0018 & 0.00099 \\
\hline & $(0.0048)$ & $(0.0047)$ & $(0.0047)$ & $(0.0040)$ & $(0.0017)$ & $(0.0020)$ & $(0.0048)$ \\
\hline \multirow[t]{2}{*}{ JSY coverage $25-50 \%$} & 0.0028 & 0.0075 & $0.013 * *$ & 0.00017 & $0.010 * * *$ & $0.0078 * * *$ & 0.0035 \\
\hline & $(0.0053)$ & $(0.0053)$ & $(0.0055)$ & $(0.0044)$ & $(0.0024)$ & $(0.0026)$ & $(0.0057)$ \\
\hline \multirow[t]{2}{*}{ JSY coverage $>50 \%$} & $0.063 * * *$ & $0.082 * * *$ & $0.10 * * *$ & $0.027 * * *$ & $0.043 * * *$ & $0.045 * * *$ & 0.010 \\
\hline & $(0.0081)$ & $(0.0084)$ & $(0.0084)$ & $(0.0057)$ & $(0.0046)$ & $(0.0037)$ & $(0.0073)$ \\
\hline Mean of dep. variable at baseline & 0.46 & 0.39 & 0.20 & 0.14 & 0.02 & 0.02 & 0.45 \\
\hline Number of observations & 342,875 & 342,875 & 342,875 & 342,875 & 342,875 & 342,875 & 340,323 \\
\hline
\end{tabular}

Notes: Data are from the DLHS-2 and the DLHS-3. *** denotes significance at 1\%, ** at 5\%, and * at 10\% level. Standard errors, corrected for clustering at the district level, are reported in parentheses. Health worker is in attendance if the birth is in a health facility or at home with a doctor, nurse, midwife, or lady health volunteer. Baseline model includes fixed effects for district and year of birth. Model with district and individual controls includes interactions between year of birth and district share of the population below the poverty line, tribal population share, and wealth asset score as well as individual controls for mother's education, husband's education, mother's age at birth, wealth asset score, recall period, and dummies for categories of urban dwelling, religion, number of live births, a multiple birth and survey round. The unit of observation is a delivery (most recent only). Deviations in sample size are due to missing data. 
Table 4. Association of JSY with Neonatal Mortality

\begin{tabular}{|c|c|c|c|c|}
\hline \multirow{3}{*}{ Dependent variable: } & \multirow{3}{*}{$\begin{array}{l}\text { Neonatal mortality } \\
\text { (1) }\end{array}$} & \multicolumn{3}{|c|}{ Disaggregated measures of mortality } \\
\hline & & 1 day mortality & Death between 2 and 28 days & Death between 8 and 28 days \\
\hline & & $(2)$ & (3) & (4) \\
\hline \multicolumn{5}{|c|}{ Panel A. Baseline model } \\
\hline \multirow[t]{2}{*}{ JSY coverage $10-25 \%$} & -0.00078 & -0.0013 & 0.00051 & 0.00026 \\
\hline & $(0.0012)$ & $(0.00085)$ & $(0.00085)$ & $(0.00049)$ \\
\hline \multirow[t]{2}{*}{ JSY coverage $25-50 \%$} & -0.00030 & -0.00048 & 0.00018 & 0.000067 \\
\hline & $(0.0013)$ & $(0.00093)$ & $(0.00092)$ & $(0.00051)$ \\
\hline \multirow[t]{2}{*}{ JSY coverage $>50 \%$} & $-0.0031 *$ & $-0.0020 *$ & -0.0011 & -0.00057 \\
\hline & $(0.0016)$ & $(0.0012)$ & $(0.0011)$ & $(0.00065)$ \\
\hline \multicolumn{5}{|c|}{ Panel B. Baseline model with district and individual controls } \\
\hline \multirow[t]{2}{*}{ JSY coverage $10-25 \%$} & -0.00043 & -0.0012 & 0.00075 & 0.00036 \\
\hline & $(0.0012)$ & $(0.00086)$ & $(0.00084)$ & $(0.00049)$ \\
\hline \multirow[t]{2}{*}{ JSY coverage $25-50 \%$} & 0.00026 & -0.00051 & 0.00077 & 0.00030 \\
\hline & $(0.0012)$ & $(0.00095)$ & $(0.00089)$ & $(0.00053)$ \\
\hline \multirow[t]{2}{*}{ JSY coverage $>50 \%$} & -0.0027 & $-0.0022 *$ & -0.00053 & -0.00029 \\
\hline & $(0.0017)$ & $(0.0012)$ & $(0.0011)$ & $(0.00066)$ \\
\hline Mean of dep. variable at baseline & 0.031 & 0.015 & 0.016 & 0.0060 \\
\hline Number of observations & 429,443 & 429,443 & 429,443 & 429,443 \\
\hline
\end{tabular}

Notes: Data are from the DLHS-2 and the DLHS-3. *** denotes significance at 1\%, ** at 5\%, and * at 10\% level. Standard errors, corrected for clustering at the district level, are reported in parentheses. Baseline model includes fixed effects for district and year of birth. Model with district and individual controls includes interactions between year of birth and district share of the population below the poverty line, tribal population share, and wealth asset score as well as individual controls for mother's education, husband's education, mother's age at birth, wealth asset score, recall period, and dummies for categories of urban dwelling, religion, number of live births, a multiple birth and survey round. The unit of observation is a live birth (based on the birth history of a woman). 
Table 5. Association of JSY with Unintended Outcomes

\begin{tabular}{|c|c|c|c|c|c|}
\hline \multirow[b]{2}{*}{ Dependent variable } & \multicolumn{2}{|c|}{ Place of delivery } & \multirow[b]{2}{*}{$\begin{array}{c}\text { Pregnant } \\
(2004-2008) \\
\text { (3) }\end{array}$} & \multicolumn{2}{|c|}{ Breastfeeding } \\
\hline & $\begin{array}{l}\text { Private health } \\
\text { facility } \\
\text { (1) }\end{array}$ & $\begin{array}{l}\text { Public health } \\
\text { facility } \\
\text { (2) }\end{array}$ & & $\begin{array}{c}\text { Within } 1 \text { hour } \\
\text { (4) }\end{array}$ & $\begin{array}{c}\text { Within } 24 \text { hours } \\
\text { (5) }\end{array}$ \\
\hline \multicolumn{6}{|c|}{ Panel A. Baseline model } \\
\hline \multirow[t]{2}{*}{ JSY coverage $10-25 \%$} & -0.0053 & -0.00072 & 0.00058 & $0.016 * *$ & $0.015 *$ \\
\hline & $(0.0041)$ & $(0.0049)$ & $(0.0011)$ & $(0.0071)$ & $(0.0082)$ \\
\hline \multirow[t]{2}{*}{ JSY coverage $25-50 \%$} & $-0.012 * * *$ & $0.019 * * *$ & 0.0011 & $0.026 * * *$ & $0.025 * * *$ \\
\hline & $(0.0042)$ & $(0.0055)$ & $(0.0012)$ & $(0.0085)$ & $(0.0096)$ \\
\hline \multirow[t]{2}{*}{ JSY coverage $>50 \%$} & $-0.034 * * *$ & $0.11 * * *$ & $0.0070 * * *$ & $0.075 * * *$ & $0.076 * * *$ \\
\hline & $(0.0047)$ & $(0.0086)$ & $(0.0019)$ & $(0.011)$ & $(0.013)$ \\
\hline \multicolumn{6}{|c|}{ Panel B. Baseline model with district and individual controls } \\
\hline \multirow[t]{2}{*}{ JSY coverage $10-25 \%$} & -0.0018 & -0.0015 & 0.0016 & $0.017 * *$ & $0.015 *$ \\
\hline & $(0.0039)$ & $(0.0047)$ & $(0.0010)$ & $(0.0072)$ & $(0.0081)$ \\
\hline \multirow[t]{2}{*}{ JSY coverage $25-50 \%$} & -0.0053 & $0.013 * *$ & $0.0026 * *$ & $0.026 * * *$ & $0.023 * *$ \\
\hline & $(0.0040)$ & $(0.0055)$ & $(0.0012)$ & $(0.0087)$ & $(0.0097)$ \\
\hline \multirow[t]{2}{*}{ JSY coverage $>50 \%$} & $-0.022 * * *$ & $0.10 * * *$ & $0.0094 * * *$ & $0.073 * * *$ & $0.069 * * *$ \\
\hline & $(0.0045)$ & $(0.0084)$ & $(0.0020)$ & $(0.012)$ & $(0.014)$ \\
\hline Mean of dep. variable at baseline & 0.19 & 0.20 & 0.086 & 0.32 & 0.54 \\
\hline Number of observations & 342,875 & 342,875 & $2,528,498$ & 336,252 & 336,252 \\
\hline
\end{tabular}

Number of observation

342,875

Notes: Data are from the DLHS-2 and the DLHS-3, except column (3) which uses pregnancy data from women in the DLHS-3 only. $* * *$ denotes significance at $1 \%, * *$ at $5 \%$, and $*$ at $10 \%$
level. Standard errors, corrected for clustering at the district level, are reported in parentheses. Standard deviation of the dependent variable mean is in square brackets. Column (3) assumes that the number of months a woman has been pregnant, if pregnant at the time of interview, is as good as random (constrained to be between three and nine months). Baseline model includes fixed effects for district and year of birth. Model with district and individual controls includes interactions between year of birth and district share of the population below the poverty line, tribal population share, and wealth asset score as well as individual controls for mother's education, husband's education, mother's age at birth, wealth asset score, recall period, and dummies for categories of urban dwelling, religion, number of live births, a multiple birth, and survey round. The unit of observation is a delivery (most recent only), except in columns ( 3 ) where it is a woman-year. 
Table 6. Heterogeneity in the Effect of the JSY on Government Facility Births

\begin{tabular}{|c|c|c|c|c|c|c|c|c|}
\hline & \multicolumn{2}{|c|}{ Education of mother } & \multicolumn{2}{|c|}{ Wealth of household } & \multicolumn{2}{|c|}{$\begin{array}{c}\text { Residence } \\
\text { (in high focus states) } \\
\end{array}$} & \multicolumn{2}{|c|}{ Focal states } \\
\hline & $\begin{array}{c}\text { No } \\
\text { education }\end{array}$ & $\begin{array}{c}\text { Some } \\
\text { education }\end{array}$ & Poorest half & Richest half & Urban & Rural & High focus & Low focus \\
\hline & (1) & (2) & (3) & (4) & (5) & $(6)$ & (7) & $(8)$ \\
\hline \multicolumn{9}{|c|}{ Panel A. Baseline model } \\
\hline \multirow{2}{*}{ JSY coverage } & $0.22 * * *$ & $0.18 * * *$ & $0.22 * * *$ & $0.18 * * *$ & $0.19 * * *$ & $0.24 * * *$ & $0.22 * * *$ & 0.0083 \\
\hline & $(0.016)$ & $(0.014)$ & $(0.017)$ & $(0.015)$ & $(0.027)$ & $(0.017)$ & $(0.017)$ & $(0.020)$ \\
\hline \multicolumn{9}{|c|}{ Panel B. Baseline model with district and individual controls } \\
\hline \multirow[t]{2}{*}{ JSY coverage } & $0.22 * * *$ & $0.18 * * *$ & $0.23 * * *$ & $0.18 * * *$ & $0.18 * * *$ & $0.24 * * *$ & $0.23 * * *$ & -0.012 \\
\hline & $(0.016)$ & $(0.014)$ & $(0.016)$ & $(0.015)$ & $(0.027)$ & $(0.017)$ & $(0.016)$ & $(0.021)$ \\
\hline Mean of dep. variable at baseline & 0.11 & 0.28 & 0.12 & 0.28 & 0.28 & 0.13 & 0.16 & 0.28 \\
\hline Number of observations & 161,813 & 181,062 & 174,488 & 168,387 & 42,155 & 191,197 & 233,352 & 109,523 \\
\hline
\end{tabular}


Figure 1. JSY Coverage and Proportion of Women Giving Birth in a Government Facility
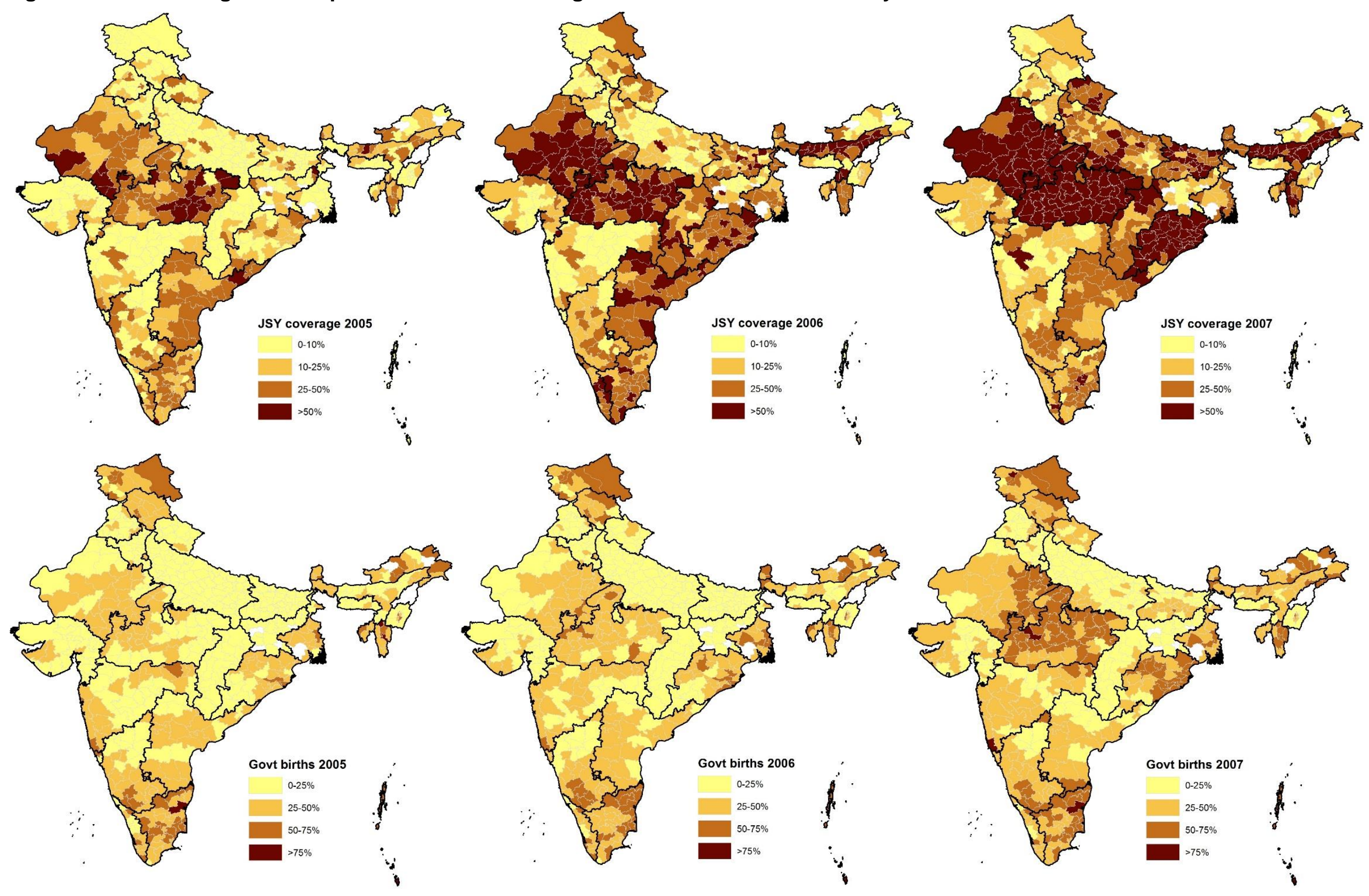


\section{Appendix}

Table A1. District Correlates of JSY Coverage

\begin{tabular}{|c|c|c|c|c|c|}
\hline & $\begin{array}{c}\text { Wealth } \\
\text { (1) }\end{array}$ & $\begin{array}{l}\text { Poverty } \\
\text { (2) }\end{array}$ & $\begin{array}{c}\text { Tribal } \\
\text { population } \\
(3) \\
\end{array}$ & $\begin{array}{c}\text { State fixed } \\
\text { effects } \\
(4)\end{array}$ & $\begin{array}{l}\text { Government } \\
\text { facility births } \\
\text { at baseline }\end{array}$ \\
\hline Average asset wealth score & $\begin{array}{c}-0.058 * * * \\
(0.0051)\end{array}$ & $\begin{array}{c}-0.051 * * * \\
(0.0053)\end{array}$ & $\begin{array}{c}-0.041 * * * \\
(0.0057)\end{array}$ & $\begin{array}{c}-0.017 * * \\
(0.0088)\end{array}$ & $\begin{array}{l}-0.018 * \\
(0.0092)\end{array}$ \\
\hline Poor share of population & & $\begin{array}{c}0.13 * * * \\
(0.032)\end{array}$ & $\begin{array}{l}0.12 * * \\
(0.032)\end{array}$ & $\begin{array}{l}0.13 * * \\
(0.055)\end{array}$ & $\begin{array}{l}0.13 * * \\
(0.056)\end{array}$ \\
\hline Tribal share of population & & & $\begin{array}{c}0.14 * * * \\
(0.030)\end{array}$ & $\begin{array}{l}-0.0053 \\
(0.037)\end{array}$ & $\begin{array}{l}-0.0053 \\
(0.037)\end{array}$ \\
\hline Government facility share of births & & & & & $\begin{array}{l}0.0059 \\
(0.044)\end{array}$ \\
\hline State fixed effects & No & No & No & Yes & Yes \\
\hline Number of observations & 1,761 & 1,761 & 1,761 & 1,761 & 1,761 \\
\hline
\end{tabular}

Notes: Data are from the DLHS-3. *** denotes significance at $1 \%, * *$ at $5 \%$, and $*$ at $10 \%$ level. Standard errors are reported in parentheses. The dependent variable is JSY coverage. The unit of observation is a district-year over the period $2005 / 06$ to 2007/08. Government facility share of births is measured at baseline (2004/05). 
Table A2. JSY as a Binary Treatment

\begin{tabular}{|c|c|c|c|c|c|c|c|c|}
\hline Dependent variable: & $\begin{array}{l}\text { Delivery in a } \\
\text { health facility } \\
\text { (1) }\end{array}$ & $\begin{array}{c}\text { Delivery in } \\
\text { public facility } \\
\text { (2) }\end{array}$ & $\begin{array}{c}\text { Delivery in } \\
\text { private facility } \\
\text { (3) }\end{array}$ & $\begin{array}{c}\text { ANC three } \\
\text { visits } \\
(4)\end{array}$ & $\begin{array}{c}\text { Neonatal } \\
\text { mortality } \\
(5)\end{array}$ & $\begin{array}{c}\text { One-day } \\
\text { mortality } \\
(6)\end{array}$ & $\begin{array}{c}\text { Pregnant } \\
(2004-08) \\
(7)\end{array}$ & $\begin{array}{c}\text { Breastfeeding } \\
\text { within } 1 \text { hour } \\
\text { (8) }\end{array}$ \\
\hline \multicolumn{9}{|c|}{ Panel A. Baseline model } \\
\hline JSY coverage > $10 \%$ & $\begin{array}{l}0.013 * * \\
(0.0054)\end{array}$ & $\begin{array}{c}0.025 * * * \\
(0.0048)\end{array}$ & $\begin{array}{c}-0.012 * * * \\
(0.0037)\end{array}$ & $\begin{array}{c}0.0040 \\
(0.0052)\end{array}$ & $\begin{array}{l}-0.00098 \\
(0.0011)\end{array}$ & $\begin{array}{c}-0.0011 \\
(0.00079)\end{array}$ & $\begin{array}{c}0.0014 \\
(0.0010)\end{array}$ & $\begin{array}{c}0.030 * * * \\
(0.0074)\end{array}$ \\
\hline \multicolumn{9}{|c|}{ Panel B. Baseline model with district and individual controls } \\
\hline JSY coverage > 10\% & $\begin{array}{l}0.013 * * * \\
(0.0046)\end{array}$ & $\begin{array}{c}0.019 * * * \\
(0.0047)\end{array}$ & $\begin{array}{c}-0.0059 * \\
(0.0035)\end{array}$ & $\begin{array}{c}0.0032 \\
(0.0048)\end{array}$ & $\begin{array}{l}-0.00050 \\
(0.0011)\end{array}$ & $\begin{array}{c}-0.0011 \\
(0.00080)\end{array}$ & $\begin{array}{l}0.0025 * * \\
(0.00099)\end{array}$ & $\begin{array}{l}0.028 * * * \\
(0.0074)\end{array}$ \\
\hline
\end{tabular}

Notes: Data are from the DLHS-2 and the DLHS-3. *** denotes significance at 1\%, ** at 5\%, and * at 10\% level. Standard errors, corrected for clustering at the district level, are reported in parentheses. Health worker is in attendance if the birth is in a health facility or at home with a doctor, nurse, midwife, or lady health volunteer. Baseline model includes fixed effects for district and year of birth. Model with district and individual controls includes interactions between year of birth and district share of the population below the poverty line, tribal population share, and wealth asset score as well as individual controls for mother's education, husband's education, mother's age at birth, wealth asset score, recall period, and dummies for categories of urban dwelling, religion, number of live births, a multiple birth and survey round. The unit of observation is a delivery (most recent only). Deviations in sample size are due to missing data. 
Table A3. JSY as a Continuous Treatment

\begin{tabular}{|c|c|c|c|c|c|c|c|c|}
\hline Dependent variable: & $\begin{array}{l}\text { Delivery in a } \\
\text { health facility } \\
\text { (1) }\end{array}$ & $\begin{array}{c}\text { Delivery in } \\
\text { public facility } \\
\text { (2) }\end{array}$ & $\begin{array}{c}\text { Delivery in } \\
\text { private facility } \\
\text { (3) }\end{array}$ & $\begin{array}{c}\text { ANC three } \\
\text { visits } \\
(4)\end{array}$ & $\begin{array}{c}\text { Neonatal } \\
\text { mortality } \\
(5)\end{array}$ & $\begin{array}{c}\text { One-day } \\
\text { mortality } \\
(6)\end{array}$ & $\begin{array}{c}\text { Pregnant } \\
(2004-08) \\
(7)\end{array}$ & $\begin{array}{c}\text { Breastfeeding } \\
\text { within } 1 \text { hour } \\
\text { (8) }\end{array}$ \\
\hline \multicolumn{9}{|c|}{ Panel A. Baseline model } \\
\hline JSY coverage & $\begin{array}{l}0.15 * * * \\
(0.015)\end{array}$ & $\begin{array}{c}0.20 * * * \\
(0.014) \\
\end{array}$ & $\begin{array}{c}-0.059 * * * \\
(0.0072)\end{array}$ & $\begin{array}{l}0.020 * \\
(0.012) \\
\end{array}$ & $\begin{array}{l}-0.0035 \\
(0.0024) \\
\end{array}$ & $\begin{array}{l}-0.0022 \\
(0.0018)\end{array}$ & $\begin{array}{c}0.013 * * * \\
(0.0030)\end{array}$ & $\begin{array}{l}0.12 * * * \\
(0.016)\end{array}$ \\
\hline \multicolumn{9}{|c|}{ Panel B. Baseline model with district and individual controls } \\
\hline JSY coverage & $\begin{array}{l}0.16 * * * \\
(0.014)\end{array}$ & $\begin{array}{l}0.20 * * * \\
(0.013)\end{array}$ & $\begin{array}{c}-0.041 * * * \\
(0.0067)\end{array}$ & $\begin{array}{c}0.023 * * \\
(0.012)\end{array}$ & $\begin{array}{l}-0.0033 \\
(0.0025)\end{array}$ & $\begin{array}{l}-0.0026 \\
(0.0019)\end{array}$ & $\begin{array}{c}0.017 * * * \\
(0.061)\end{array}$ & $\begin{array}{l}0.12 * * * \\
(0.017)\end{array}$ \\
\hline
\end{tabular}




\section{Table A4. Association of JSY with Medical Procedures at Childbirth}

Dependent variable:

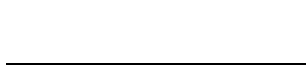

Caesarean section

(1)

Panel A. Baseline model

$\begin{array}{ccc}\text { JSY coverage } 10-25 \% & -0.0038 & 0.0012 \\ \text { JSY coverage } 25-50 \% & (0.0026) & (0.0020) \\ & -0.0032 & 0.0019 \\ \text { JSY coverage }>50 \% & (0.0028) & (0.0022) \\ & -0.013 * * * & 0.0076 * * * \\ & (0.0032) & (0.0027)\end{array}$

Panel B. Baseline model with district and individual controls

\begin{tabular}{lcc} 
JSY coverage $10-25 \%$ & -0.0021 & 0.0014 \\
JSY coverage $25-50 \%$ & $(0.0024)$ & $(0.0020)$ \\
& 0.00081 & 0.0016 \\
JSY coverage $>50 \%$ & $(0.0027)$ & $0.0023)$ \\
& $-0.0054 *$ & $0.0066 * *$ \\
\hline Mean of dependent variable at baseline & $(0.0031)$ & $0.0028)$ \\
Number of observations & 0.075 & 342,853
\end{tabular}

Notes: Data are from the DLHS-2 and the DLHS-3. *** denotes significance at $1 \%$, ** at 5\%, and * at 10\% level. Standard errors, corrected for clustering at the district level, are reported in parentheses. Standard deviation of the dependent variable mean is in square brackets. Assisted delivery involves the use of forceps or a ventouse. Baseline model includes fixed effects for district and year of birth. Model with district and individual controls includes interactions between year of birth and district share of the population below the poverty line, tribal population share, and wealth asset score as well as individual controls for mother's education, husband's education, mother's age at birth, wealth asset score, recall period, and dummies for categories of urban dwelling, religion, number of live births, a multiple birth, and survey round. 
Table A5. Differences in Pre-Trends

\begin{tabular}{|c|c|c|c|c|}
\hline & $\begin{array}{l}\text { Delivery in a } \\
\text { facility } \\
\text { (1) }\end{array}$ & $\begin{array}{c}\text { Delivery in } \\
\text { public facility } \\
\text { (2) }\end{array}$ & $\begin{array}{c}\text { Neonatal } \\
\text { mortality } \\
\text { (3) }\end{array}$ & $\begin{array}{l}\text { One-day } \\
\text { mortality } \\
\text { (4) }\end{array}$ \\
\hline \multicolumn{5}{|c|}{ Panel A. Baseline model } \\
\hline \multirow[t]{2}{*}{ Time } & $0.011 * * *$ & $0.0042 *$ & $-0.0046 * * *$ & $-0.0027 * * *$ \\
\hline & $(0.0024)$ & $(0.0021)$ & $(0.00060)$ & $(0.00039)$ \\
\hline \multirow[t]{2}{*}{ Time $\mathrm{x}$ JSY coverage } & $-0.011 *$ & 0.0057 & 0.00027 & 0.0013 \\
\hline & $(0.0064)$ & $(0.0058)$ & $(0.0017)$ & $(0.0010)$ \\
\hline \multicolumn{5}{|c|}{ Panel B. Baseline model with district and individual controls } \\
\hline \multirow[t]{2}{*}{ Time } & -0.00019 & -0.0086 & $0.0045 * * *$ & 0.0014 \\
\hline & $(0.0056)$ & $(0.0064)$ & $(0.0017)$ & $(0.0012)$ \\
\hline \multirow[t]{2}{*}{ Time $\mathrm{x}$ JSY coverage } & -0.00071 & 0.0090 & 0.0020 & $0.0020 *$ \\
\hline & $(0.0057)$ & $(0.0058)$ & $(0.0017)$ & $(0.0011)$ \\
\hline Mean of dependent variable & 0.39 & 0.20 & 0.033 & 0.016 \\
\hline Number of observations & 168,887 & 168,887 & 226,567 & 226,567 \\
\hline
\end{tabular}

Notes: Data are from the DLHS-2 and the DLHS-3 but are for the period before the start of the JSY only. *** denotes significance at $1 \%, * *$ at $5 \%$, and $*$ at $10 \%$ level. Baseline model includes time (birth year since start of data period), an interaction between time and coverage of the JSY, and fixed effects for district. Model with district and individual controls includes interactions between year of birth and district share of the population below the poverty line, tribal population share, and wealth asset score as well as individual controls for mother's education, husband's education, mother's age at birth, wealth asset score, recall period, and dummies for categories of urban dwelling, religion, number of live births, a multiple birth, and survey round. 
Table A6. Correlation between JSY Coverage and Demographics

\begin{tabular}{|c|c|c|c|}
\hline & $\begin{array}{c}\text { JSY coverage } \\
\text { (1) }\end{array}$ & $\begin{array}{c}\text { JSY coverage } \\
(2)\end{array}$ & $\begin{array}{l}\text { Delivery in a } \\
\text { health facility } \\
\text { (3) }\end{array}$ \\
\hline \multirow[t]{2}{*}{ Urban } & -0.00050 & -0.00067 & $0.049 * * *$ \\
\hline & $(0.00097)$ & $(0.00090)$ & -0.0052 \\
\hline \multirow[t]{2}{*}{ Hindu } & -0.00069 & -0.00047 & $0.030 * * *$ \\
\hline & $(0.00091)$ & $(0.00085)$ & -0.005 \\
\hline \multirow[t]{2}{*}{ Scheduled caste } & -0.00025 & 0.000036 & $0.026 * * *$ \\
\hline & $(0.0010)$ & $(0.00098)$ & -0.0049 \\
\hline \multirow[t]{2}{*}{ Scheduled tribe } & 0.00054 & 0.00034 & $-0.049 * * *$ \\
\hline & $(0.0013)$ & $(0.0012)$ & -0.0073 \\
\hline \multirow[t]{2}{*}{ "Other backward" ethnicity } & 0.00028 & 0.00045 & 0.0034 \\
\hline & $(0.00082)$ & $(0.00076)$ & -0.0045 \\
\hline \multirow[t]{2}{*}{ Woman's education (grades completed) } & $-0.00016 *$ & -0.00014 & $0.0040 * * *$ \\
\hline & $(0.000093)$ & $(0.000086)$ & -0.00043 \\
\hline \multirow[t]{2}{*}{ Husband's education (grades completed) } & 0.000028 & 0.000077 & $0.0018 * * *$ \\
\hline & $(0.000084)$ & $(0.000079)$ & -0.00032 \\
\hline \multirow[t]{2}{*}{ Two live births } & $0.0030 * * *$ & $0.0014 *$ & $-0.048 * * *$ \\
\hline & $(0.00089)$ & $(0.00082)$ & -0.0036 \\
\hline \multirow[t]{2}{*}{ Three live births } & $0.0033 * * *$ & $0.0025 * *$ & $-0.068 * * *$ \\
\hline & $(0.0011)$ & $(0.0011)$ & -0.0046 \\
\hline \multirow[t]{2}{*}{ Four live births } & 0.0011 & 0.00080 & $-0.091 * * *$ \\
\hline & $(0.0013)$ & $(0.0012)$ & -0.0052 \\
\hline \multirow[t]{2}{*}{ Five or more live births } & 0.00063 & 0.0014 & $-0.100 * * *$ \\
\hline & $(0.0014)$ & $(0.0013)$ & -0.0061 \\
\hline \multirow[t]{2}{*}{ Mother's age at childbirth (years) } & -0.000094 & -0.00011 & 0.00018 \\
\hline & $(0.000085)$ & $(0.000079)$ & -0.00032 \\
\hline \multirow[t]{2}{*}{ Wealth asset score } & 0.00026 & 0.0000095 & $-0.0027 * *$ \\
\hline & $(0.00022)$ & $(0.00020)$ & -0.0012 \\
\hline \multirow[t]{2}{*}{ Multiple birth } & 0.0027 & 0.0024 & $0.069 * * *$ \\
\hline & $(0.0028)$ & $(0.0026)$ & -0.011 \\
\hline District controls & No & Yes & Yes \\
\hline$F(14,586)$ & 2.01 & 1.18 & 57.72 \\
\hline$p$-value & 0.015 & 0.290 & $<0.001$ \\
\hline Number of observations & 173,988 & 173,988 & 173,988 \\
\hline Number of districts & 587 & 587 & 587 \\
\hline
\end{tabular}

Notes: Data are from the DLHS-2 and the DLHS-3. $* * *$ denotes significance at $1 \%$, ** at $5 \%$, and $*$ at $10 \%$ level. Standard errors, corrected for clustering at the district level, are reported in parentheses. Regressions includes fixed effects for district and year of birth, as well as the variables reported. Regression in column (2) and (3) further include interactions between year of birth and district share of the population below the poverty line, tribal population share, and mean wealth asset score. 
Table A7. Further Robustness Checks

\begin{tabular}{|c|c|c|c|c|c|}
\hline & $\begin{array}{c}\text { Delivery in } \\
\text { public facility } \\
\text { (1) }\end{array}$ & $\begin{array}{c}\text { Delivery in } \\
\text { private facility } \\
\text { (2) }\end{array}$ & $\begin{array}{l}\text { One-day } \\
\text { mortality } \\
\text { (3) }\end{array}$ & $\begin{array}{c}\text { Pregnant } \\
(2004-08) \\
(4)\end{array}$ & $\begin{array}{c}\text { Breastfeeding } \\
\text { within } 1 \text { hour } \\
\text { (5) }\end{array}$ \\
\hline \multicolumn{6}{|c|}{ Panel A. Three-year long differences $(2001,2004,2007)$} \\
\hline JSY coverage $10-25 \%$ & $\begin{array}{r}-0.0014 \\
(0.012)\end{array}$ & $\begin{array}{l}0.0028 \\
(0.010)\end{array}$ & $\begin{array}{l}-0.0020 \\
(0.0024)\end{array}$ & $\mathrm{n} / \mathrm{a}$ & $\begin{array}{l}0.0057 \\
(0.019)\end{array}$ \\
\hline JSY coverage $25-50 \%$ & $\begin{array}{c}0.026 * * \\
(0.012)\end{array}$ & $\begin{array}{l}0.00085 \\
(0.0100)\end{array}$ & $\begin{array}{l}0.00082 \\
(0.0025)\end{array}$ & $\mathrm{n} / \mathrm{a}$ & $\begin{array}{l}0.0061 \\
(0.019)\end{array}$ \\
\hline JSY coverage $>50 \%$ & $\begin{array}{l}0.17 * * * \\
(0.014)\end{array}$ & $\begin{array}{l}-0.024 * * \\
(0.0096)\end{array}$ & $\begin{array}{l}-0.0014 \\
(0.0025)\end{array}$ & $\mathrm{n} / \mathrm{a}$ & $\begin{array}{c}0.091 * * * \\
(0.019)\end{array}$ \\
\hline \multicolumn{6}{|c|}{ Panel B. Exclude high mortality districts } \\
\hline JSY coverage $10-25 \%$ & $\begin{array}{l}-0.00071 \\
(0.0050)\end{array}$ & $\begin{array}{l}-0.0032 \\
(0.0042)\end{array}$ & $\begin{array}{l}-0.00084 \\
(0.00081)\end{array}$ & $\begin{array}{l}0.0018 * \\
(0.0011)\end{array}$ & $\begin{array}{l}0.020 * * * \\
(0.0075)\end{array}$ \\
\hline JSY coverage $25-50 \%$ & $\begin{array}{l}0.015 * * \\
(0.0057)\end{array}$ & $\begin{array}{l}-0.0059 \\
(0.0042)\end{array}$ & $\begin{array}{l}-0.000059 \\
(0.00091)\end{array}$ & $\begin{array}{l}0.0027 * * \\
(0.0013)\end{array}$ & $\begin{array}{l}0.026 * * * \\
(0.0090)\end{array}$ \\
\hline JSY coverage $>50 \%$ & $\begin{array}{l}0.10 * * * \\
(0.0086)\end{array}$ & $\begin{array}{c}-0.023 * * * \\
(0.0047)\end{array}$ & $\begin{array}{l}-0.0018 \\
(0.0012)\end{array}$ & $\begin{array}{c}0.0097 * * * \\
(0.0021)\end{array}$ & $\begin{array}{c}0.071 * * * \\
(0.012)\end{array}$ \\
\hline \multicolumn{6}{|c|}{ Panel C. Exclude low priority states } \\
\hline JSY coverage $10-25 \%$ & $\begin{array}{l}-0.0016 \\
(0.0064)\end{array}$ & $\begin{array}{r}-0.00027 \\
(0.0046)\end{array}$ & $\begin{array}{l}-0.00060 \\
(0.0011)\end{array}$ & $\begin{array}{l}0.00091 \\
(0.0015)\end{array}$ & $\begin{array}{l}0.026 * * * \\
(0.0098)\end{array}$ \\
\hline JSY coverage $25-50 \%$ & $\begin{array}{l}0.017 * * \\
(0.0075)\end{array}$ & $\begin{array}{l}-0.0039 \\
(0.0048)\end{array}$ & $\begin{array}{l}-0.00060 \\
(0.0011)\end{array}$ & $\begin{array}{c}0.0016 \\
(0.0017)\end{array}$ & $\begin{array}{c}0.046 * * * \\
(0.012)\end{array}$ \\
\hline JSY coverage $>50 \%$ & $\begin{array}{l}0.11 * * * \\
(0.010)\end{array}$ & $\begin{array}{c}-0.021 * * * \\
(0.0056)\end{array}$ & $\begin{array}{c}-0.0028 * * \\
(0.0013)\end{array}$ & $\begin{array}{c}0.0090 * * * \\
(0.0025)\end{array}$ & $\begin{array}{c}0.089 * * * \\
(0.015)\end{array}$ \\
\hline \multicolumn{6}{|c|}{ Panel D. State-specific time trends } \\
\hline JSY coverage $10-25 \%$ & $\begin{array}{c}-0.0096 * * \\
(0.0043)\end{array}$ & $\begin{array}{l}-0.0016 \\
(0.0036)\end{array}$ & $\begin{array}{c}-0.0011 \\
(0.00088)\end{array}$ & $\begin{array}{c}0.0029 * * * \\
(0.0010)\end{array}$ & $\begin{array}{l}0.013 * * \\
(0.0056)\end{array}$ \\
\hline JSY coverage $25-50 \%$ & $\begin{array}{l}-0.010 * * \\
(0.0049)\end{array}$ & $\begin{array}{l}-0.0017 \\
(0.0037)\end{array}$ & $\begin{array}{l}-0.0011 \\
(0.0010)\end{array}$ & $\begin{array}{c}0.0040 * * * \\
(0.0012)\end{array}$ & $\begin{array}{c}0.011 \\
(0.0065)\end{array}$ \\
\hline JSY coverage $>50 \%$ & $\begin{array}{l}0.033 * * * \\
(0.0078)\end{array}$ & $\begin{array}{l}-0.010 * * \\
(0.0044)\end{array}$ & $\begin{array}{l}-0.0023 * \\
(0.0013)\end{array}$ & $\begin{array}{l}0.0052 * * \\
(0.0021)\end{array}$ & $\begin{array}{c}0.016 \\
(0.010)\end{array}$ \\
\hline
\end{tabular}

Notes: Data are from the DLHS-2 and the DLHS-3. *** denotes significance at 1\%, ** at 5\%, and * at 10\% level. All estimates are from a model that includes fixed effects for district and year of birth, interactions between year of birth and district share of the population below the poverty line, tribal population share, and wealth asset score as well as individual controls for mother's education, husband's education, mother's age at birth, wealth asset score, recall period, and dummies for categories of urban dwelling, religion, number of live births, a multiple birth, and survey round. 


\section{Online Appendix (Not for Publication)}

\section{A. Comparison to Lim et al (2010)}

Lim et al (2010) present estimates of the effect of the JSY using the same survey data we use but different empirical methods. They produce estimates based on three alternative methods of analysis: exact matching, with versus without, and a difference-in-difference analysis. The first two methods are based on individual level data while the latter uses data aggregated at the district level. We compare results to examine whether there are differences. While such a comparison cannot in itself explain why there are differences, our critical review of the methods used by Lim et al (2010) in Section II.C suggests that there are some important sources of potential bias in their estimates of effect.

A comparison of the effect estimates between the two studies is complicated by the fact that treatment is defined differently. Lim et al (2010) define treatment as whether the woman reports receiving the JSY cash. In their difference-in-difference analysis, treatment is defined analogously as the district fraction of births receiving the JSY cash. By contrast, we define treatment as the district fraction of births in a public health facility in which the woman receives the JSY cash, and then generate categories of JSY coverage for the empirical analysis.

To make a comparison between the two studies more meaningful we report estimates in which our treatment variable, JSY coverage, enters the regression as a continuous variable. These are the same estimates as those reported in Table A3 of the Appendix. While this goes some way to improving comparability, differences in the definition of treatment between the two studies remain and this should be kept in mind when interpreting the findings.

Table 1. Comparison with Lim et al (2010)

\begin{tabular}{|c|c|c|c|c|}
\hline & \multicolumn{3}{|c|}{ Lim et al (2010) } & \multirow{2}{*}{$\begin{array}{c}\begin{array}{c}\text { Powell-Jackson } \\
\text { et al (2015) }\end{array} \\
\text { Diff-in-diff } \\
(4)\end{array}$} \\
\hline & $\begin{array}{c}\text { Exact matching } \\
\text { (1) }\end{array}$ & $\begin{array}{l}\text { With versus } \\
\text { without } \\
\text { (2) }\end{array}$ & $\begin{array}{c}\text { Diff-in-diff } \\
\text { (3) }\end{array}$ & \\
\hline ANC 3 visits or more (\%) & $\begin{array}{c}10.7 \\
(9.1 \text { to } 12.3)\end{array}$ & $\begin{array}{c}11.1 \\
(10.1 \text { to } 12.1)\end{array}$ & $\begin{array}{c}10.9 \\
(4.6 \text { to } 17.2)\end{array}$ & $\begin{array}{c}2.3 \\
(0.05 \text { to } 4.6)\end{array}$ \\
\hline Facility birth (\%) & $\begin{array}{c}43.5 \\
(42.5 \text { to } 44.6)\end{array}$ & $\begin{array}{c}43.9 \\
(43.3 \text { to } 44.6)\end{array}$ & $\begin{array}{c}49.2 \\
(43.2 \text { to } 55.1)\end{array}$ & $\begin{array}{c}16.0 \\
(13.6 \text { to } 19.0)\end{array}$ \\
\hline Neonatal deaths (per 1,000) & $\begin{array}{c}-2.3 \\
(-3.7 \text { to }-0.9)\end{array}$ & $\begin{array}{c}-2.4 \\
(-4.1 \text { to }-0.7)\end{array}$ & $\begin{array}{c}-6.2 \\
(-20.4 \text { to } 8.1)\end{array}$ & $\begin{array}{c}-3.3 \\
(-8.3 \text { to } 1.6)\end{array}$ \\
\hline
\end{tabular}

Notes: Confidence intervals are reported in parentheses. The treatment effects are in percentage points (ANC $3+$, facility births) or deaths per 1,000 (neonatal mortality).

Our findings are much less encouraging than those of Lim et al (2010) in terms of the effects on healthcare utilisation (Table 1). There is roughly a threefold difference between the two studies in the effect on facility births and the difference is similar when use of antenatal care is the outcome. The estimates of impact on neonatal mortality are of the same order magnitude in the two studies. The main difference lies in the fact that the mortality effects in Lim et al (2010) are statistically 
significant in two of the three identification strategies they use. The confidence interval around our negative effect of 3.3 deaths per 1,000 means we are unable to reject a modest effect of the JSY on neonatal mortality.

\section{B. Pre-trends}

Figure 1 to Figure 4 use data prior to the official start of the JSY to show trends for districts categorised according to different levels of JSY coverage as measured in 2007/08. Pre-trends are shown for the proportion of women giving birth in a facility, the proportion of women giving birth in government facility, neonatal mortality per 1,000 live births and one-day mortality per 1,000 live births. For each outcome, we can see that the trends are similar between different groups of JSY coverage.

Figure 1. Pre-trends for Facility Births

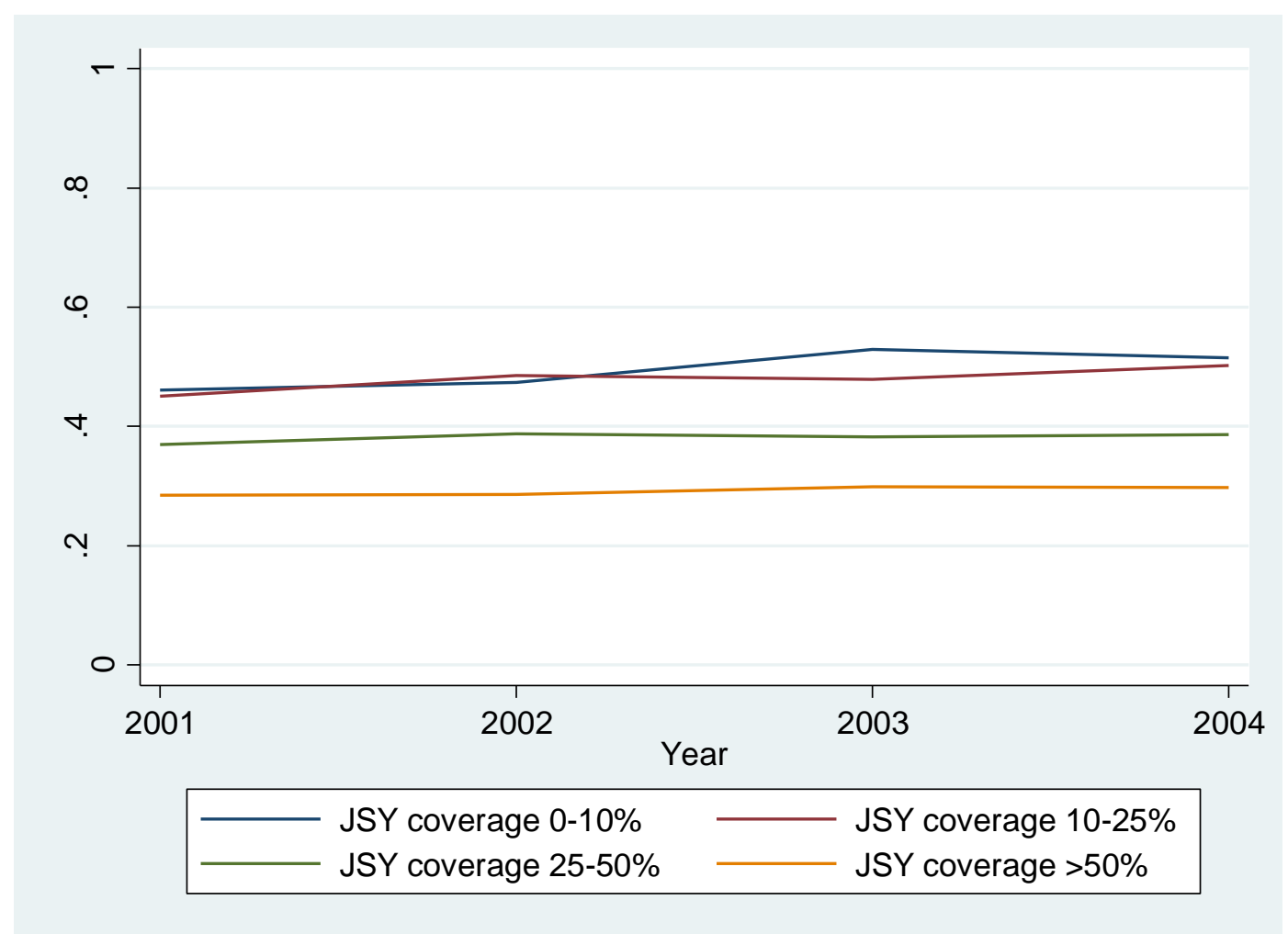


Figure 2. Pre-trends for Government Facility Births

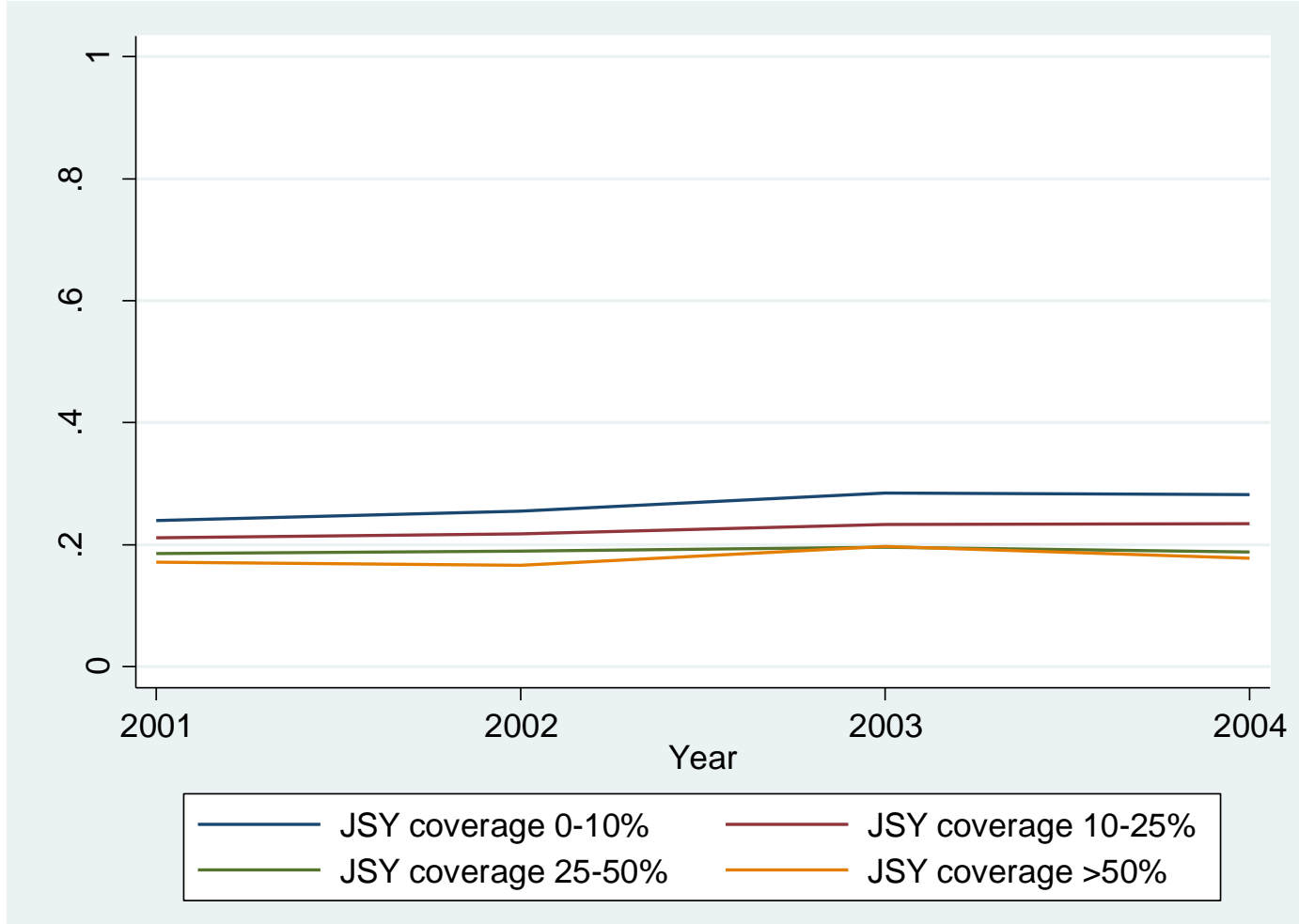

Figure 3. Pre-trends for Neonatal Mortality

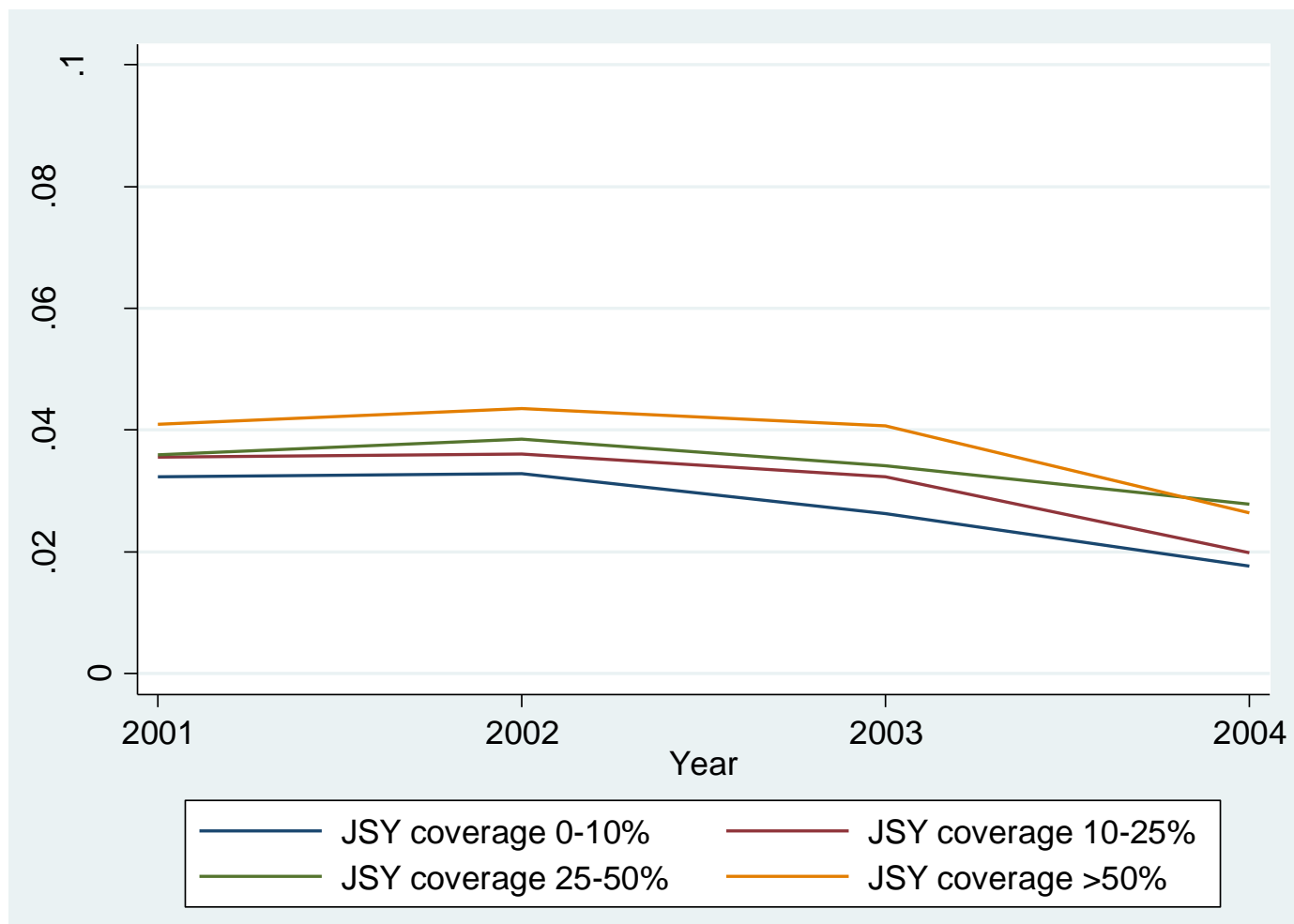


Figure 4. Pre-trends for One-Day Mortality

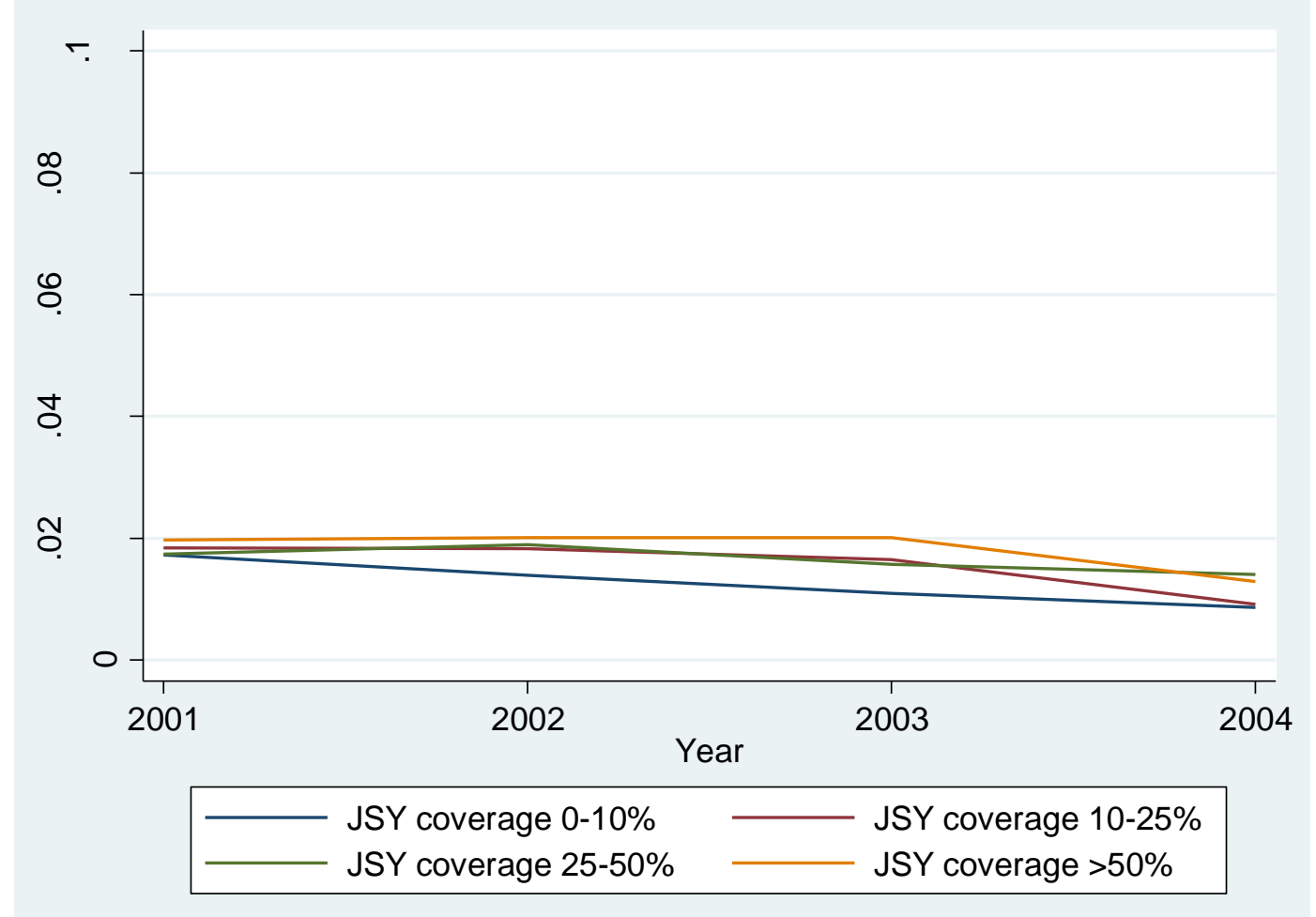




\section{References}

Babiarz KS, et al. New evidence on the impact of China's New Rural Cooperative Medical Scheme and its implications for rural primary healthcare: multivariate difference-in-difference analysis. BMJ 2010;341; c5617.

Baird SJ, et al. Effect of a cash transfer programme for schooling on prevalence of HIV and herpes simplex type 2 in Malawi: a cluster randomised trial. Lancet 2012;379; 1320-1329.

Banerjee AV, et al. Improving immunisation coverage in rural India: clustered randomised controlled evaluation of immunisation campaigns with and without incentives. BMJ 2010;340; c2220.

Bhutta ZA, et al. What works? Interventions for maternal and child undernutrition and survival. Lancet $2008 ; 371 ; 417-440$.

Bhutta ZA, et al. Countdown to 2015 decade report (2000-10): taking stock of maternal, newborn, and child survival. Lancet 2010;375; 2032-2044.

Bonu S, et al. Incidence and correlates of 'catastrophic' maternal health care expenditure in India. Health Policy Plann 2009;24; 445-456.

Campbell OM, Graham WJ. Strategies for reducing maternal mortality: getting on with what works. Lancet 2006;368; 1284-1299.

Chaturvedi S, et al. Quality of obstetric referral services in India's JSY cash transfer programme for institutional births: a study from Madhya Pradesh province. PloS one 2014;9; e96773.

Chaudhury N, et al. Missing in action: teacher and health worker absence in developing countries. J Econ Perspect 2006;20; 91-116.

Costello A, et al. An alternative strategy to reduce maternal mortality. Lancet 2006;368; 1477-1479.

Darmstadt GL, et al. Evidence-based, cost-effective interventions: how many newborn babies can we save? Lancet 2005;365; 977-988.

Das J, Hammer J. 2006. The Quality of Medical Care in India. In: Basu K (Ed)^(Eds), The Oxford Companion to Economics in India. Oxford University Press: New Delhi, India; 2006.

Das J, Hammer J. Money for nothing: The dire straits of medical practice in Delhi, India. J Dev Econ $2007 ; 83 ; 1-36$.

Das J, et al. The quality of medical advice in low-income countries. J Econ Perspect 2008;22; 93-114.

Deaton A. Instruments, Randomization, and Learning about Development. J Econ Lit 2010;48; 424455.

Devadasan N, et al. 2008. A conditional cash assistance programme for promoting institutional deliveries among the poor in India: process evaluation results. In: Richard F, Witter S, de Brouwere $\mathrm{V}(\mathrm{Ed})^{\wedge}(\mathrm{Eds})$, Reducing financial barriers to obstetric care in low-income countries. ITM: Antwerp; 2008.

Dugger C. 2004. To Help Poor Be Pupils, Not Wage Earners, Brazil Pays Parents. (Ed)^(Eds), New York Times. New York City; 2004.

Fernald LC, et al. Role of cash in conditional cash transfer programmes for child health, growth, and development: an analysis of Mexico's Oportunidades. Lancet 2008;371; 828-837.

Finkelstein A, et al. 2011. The Oregon Health Insurance Experiment Evidence from the First Year. $(E d)^{\wedge}(E d s)$, NBER working paper series no. w17190. National Bureau of Economic Research: Cambridge, Mass.; 2011.

Fiszbein A, Schady N. Conditional cash transfers: reducing present and future povertys. World Bank: Washington DC; 2009. 
Gertler P. 2000. Final report: the impact of PROGESA on health. (Ed)^(Eds). International Food Policy Research Institute: Washington DC; 2000.

Gertler P. Do conditional cash transfers improve child health? Evidence from PROGRESA's control randomized experiment. Am Econ Rev 2004;94; 336-341.

Gertler P, Van der Gaag J. The willingness to pay for medical care: evidence from two developing countriess. Johns Hopkins University Press: Baltimore and London; 1990.

Hulton LA, et al. Applying a framework for assessing the quality of maternal health services in urban India. Soc Sci Med 2007;64; 2083-2095.

Human Rights Watch. No Tally of Anguish: Accountability of Maternal Health Care in Indias. Human Rights Watch: New York; 2009.

Hunter BM, et al. Demand-side Financing and Promotion of Maternal Health: What Has India Learnt? Economic and Political Weekly 2014;159.

Imbens GW, Wooldridge JM. Recent Developments in the Econometrics of Program Evaluation. J Econ Lit 2009;47; 5-86.

International Institute for Population Sciences. National Family Health Survey (MCH and Family Planning), India 1992-93s. IIPS: Mumbai; 1995.

International Institute for Population Sciences. District Level Household and Facility Survey (DLHS3), 2007-08: Indias. IIPS: Mumbai; 2010.

International Institute for Population Sciences, Macro International. National Family Health Survey (NFHS-3), 2005-06: India: Volume Is. IIPS: Mumbai; 2007.

Jeffery P, Jeffery R. Only when the boat has started sinking: a maternal death in rural north India. Soc Sci Med 2010;71; 1711-1718.

Jensen R, Oster E. The Power of TV: Cable Television and Women's Status in India. Q J Econ 2009;124.

Jones G, et al. How many child deaths can we prevent this year? Lancet 2003;362; 65-71.

Kassebaum NJ, et al. Global, regional, and national levels and causes of maternal mortality during 19902013: a systematic analysis for the Global Burden of Disease Study 2013. Lancet 2014.

King G, et al. Public policy for the poor? A randomised assessment of the Mexican universal health insurance programme. Lancet 2009;373; 1447-1454.

Lagarde $\mathrm{M}$, et al. Conditional cash transfers for improving uptake of health interventions in low- and middle-income countries: a systematic review. JAMA 2007;298; 1900-1910.

Lim SS, et al. India's Janani Suraksha Yojana, a conditional cash transfer programme to increase births in health facilities: an impact evaluation. Lancet 2010;375; 2009-2023.

Malini S, et al. A rapid appraisal on functioning of Janani Suraksha Yojana in South Orissa. Health and Population: Perspectives and Issues 2008;31; 126-131.

Maluccio J, Flores R. 2005. Impact evaluation of a conditional cash transfer program: the Nicaraguan Red de Protección Social. (Ed)^(Eds). International Food Policy Research Insitute: Washington DC; 2005.

Manning WG, et al. Health-Insurance and the Demand for Medical-Care - Evidence from a Randomized Experiment. Am Econ Rev 1987;77; 251-277.

Marteau TM, et al. Using financial incentives to achieve healthy behaviour. BMJ 2009;338; b1415.

Mills A, et al. What do we mean by rigorous health-systems research? Lancet 2008;372; 1527-1529.

Ministry of Health and Family Welfare. 2005. National Rural Health Mission: Mission Document. $(\text { Ed })^{\wedge}($ Eds). Government of India: Delhi; 2005.

Ministry of Health and Family Welfare. 2006. Janani Suraksha Yojana: features \& frequently asked questions and answers. (Ed)^(Eds). Government of India: New Delhi; 2006. 
Morris S, et al. Monetary incentives in primary health care and effects on use and coverage of preventive health care interventions in rural Honduras: cluster randomised trial. Lancet 2004a;364; 2030-2037.

Morris SS, et al. Conditional cash transfers are associated with a small reduction in the rate of weight gain of preschool children in northeast Brazil. J Nutr 2004b;134; 2336-2341.

Muralidharan K, et al. 2011. Is There a Doctor in the House? Medical Worker Absence in India. $(\mathrm{Ed})^{\wedge}(\mathrm{Eds}) .2011$.

Murray SF, et al. Effects of demand-side financing on utilisation, experiences and outcomes of maternity care in low- and middle-income countries: a systematic review. BMC pregnancy and childbirth 2014;14; 30 .

Nagpal J, et al. Widespread non-adherence to evidence-based maternity care guidelines: a populationbased cluster randomised household survey. BJOG : an international journal of obstetrics and gynaecology 2015;122; 238-247.

Paxson C, Schady N. 2008. Does money matter? The effects of cash transfers on child health and development in rural Ecuador. (Ed)^(Eds). World Bank: Washington DC; 2008.

Registrar General of India. 2006. Maternal Mortality in India: 1997-2003: Trends, Causes And Risk Factors. (Ed)^(Eds). Office of the Registrar General of India: New Delhi; 2006.

Registrar General of India. 2013. Special Bulletin on Maternal Mortality in India: 2010-12. (Ed)^(Eds). Office of the Registrar General of India: New Delhi; 2013.

Rohde J, et al. 30 years after Alma-Ata: has primary health care worked in countries? Lancet 2008;372; 950-961.

Sood N, et al. Government health insurance for people below poverty line in India: quasi-experimental evaluation of insurance and health outcomes. BMJ 2014;349; g5114.

Stanton CK, et al. Direct observation of uterotonic drug use at public health facility-based deliveries in four districts in India. International journal of gynaecology and obstetrics: the official organ of the International Federation of Gynaecology and Obstetrics 2014;127; 25-30.

Stecklov G, et al. Demographic externalities from poverty programs in developing countries: experimental evidence from Latin Americas. American University Department of Economics: Washington DC 2006.

Thornton RL. The Demand for, and Impact of, Learning HIV Status. Am Econ Rev 2008;98; 18291863.

Thornton RL, et al. Social security health insurance for the informal sector in Nicaragua: a randomized evaluation. Health Econ 2010;19 Suppl; 181-206.

UNFPA. Concurrent Assessment of Janani Suraksha Yojana in Selected States - Bihar, Madhya Pradesh, Orissa, Rajasthan and Uttar Pradeshs. UNFPA: New Delhi; 2009.

United Nations. Global Strategy for Women's and Children's Healths. United Nations, Office of the Secretary General: New York; 2010.

Verma D, et al. Increasing Institutional Delivery and Acess to Emergency Obstetric Care Services in Rural Uttar Pradesh. The Journal of Family Welfare 2010;56; 23-30.

Wagstaff A, et al. Extending health insurance to the rural population: an impact evaluation of China's new cooperative medical scheme. J Health Econ 2009;28; 1-19.

Zhu BP, et al. Effect of the interval between pregnancies on perinatal outcomes. N Engl J Med 1999;340; 589-594. 